Draft of July 22, 2020

\title{
Lay evaluations of police and civilian use of force: Moral and physical magnitude ratings of officer and civilian actions
}

\author{
Bradley D. Celestin \& John K. Kruschke
}

Bethel College \& Indiana University

\begin{abstract}
Most police agencies in the United States, when choosing appropriate force options relative to civilian resistance, rely on a rank-ordered categorization of forceful actions. We had participants rate the moral and physical severity of officer reactions to civilian actions, and vice versa. The actions were representative of the entire range of force options in official police policy and realistic police-civilian conflicts. Results showed that ratings of moral severity of a reaction decreased as severity of the initial action increased, and that ratings of both police and civilian reactions were modulated by individual differences in beliefs about police legitimacy. High-legitimacy participants tended to rate lethal police actions following lethal civilian actions as acceptable, but low-legitimacy participants rated lethal police actions much lower. Thus, higher legitimacy seems to yield a willingness to accept lethal police force if civilian resistance is sufficiently severe, while individuals with low legitimacy may never perceive lethal police actions as acceptable. Similarly, low-legitimacy participants were much more accepting of civilian violence against police than high-legitimacy participants, and rated violent civilian reactions as deserving less severe punishment. Finally, even when actions and re-actions were exactly matched, more severe officer and civilian actions both tended to be perceived as somewhat excessive for all participants regardless of legitimacy beliefs, though likely for different reasons. These results provide novel insights that extend what we currently know about factors that shape judgments of civilian violence and, specifically, broaden the extent to which legitimacy beliefs affect moral judgments of everyone involved in police-civilian conflicts.
\end{abstract}

Keywords: Use of force, police, morality, violence, Bayesian estimation, individual differences, legitimacy 


\section{Contents}

Police and civilian perspectives on use of force 4

Six ordinal levels of force $(\mathrm{SOLOF}) \ldots \ldots \ldots \ldots$

Individual differences: legitimacy beliefs . . . . . . . . . . . . . . . 6

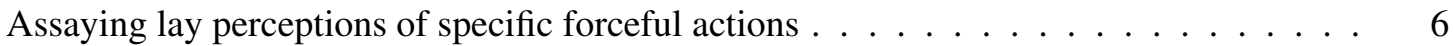

$\begin{array}{ll}\text { Method } & 7\end{array}$

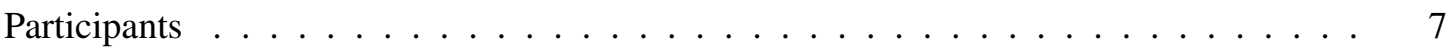

Design ............................ 7

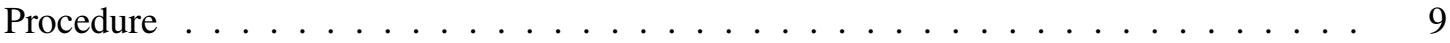

$\begin{array}{ll}\text { Results } & 12\end{array}$

Data transformation and regression model $\ldots \ldots \ldots \ldots \ldots$

Bayesian Methods . . . . . . . . . . . . . . . . . . . . . . . 14

Estimates of regression coefficients . . . . . . . . . . . . . . . . 15

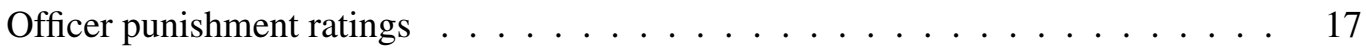

Officer acceptability ratings . . . . . . . . . . . . . . . . . . . 18

Officer appropriateness ratings $\ldots \ldots \ldots 20 \ldots$

Officer force ratings . . . . . . . . . . . . . . . . . . 23

Summary of officer action ratings $\ldots \ldots \ldots . \ldots . \ldots . \ldots 24$

Civilian punishment ratings . . . . . . . . . . . . . . . . . . . . . . . . 25

Civilian acceptability ratings $\ldots \ldots \ldots 26$

Civilian appropriateness ratings . . . . . . . . . . . . . . . . . 27

Civilian force ratings . . . . . . . . . . . . . . . . . . . . . . . 29

Summary of civilian action ratings $\ldots \ldots \ldots \ldots$

$\begin{array}{ll}\text { Discussion and Conclusions } & 31\end{array}$

$\begin{array}{ll}\text { Limitations and Future Work } & 33\end{array}$

$\begin{array}{ll}\text { Conclusions } & 34\end{array}$

$\begin{array}{ll}\text { References } & 35\end{array}$ 
In the United States, police use of force is constrained by the fourth amendment of the Constitution. But evaluating the appropriateness of any particular application of violence by police is a complex endeavor that requires attending to myriad circumstantial details. In fact, the U.S. Supreme Court declared that judging whether or not police use of force is reasonable is so idiosyncratic that it "is not capable of precise definition or mechanical application" (Bell v. Wolfish, 441 U.S. 520, 1979). Nevertheless, law enforcement agencies must provide guidance to officers in the field, and during the past century agencies have developed detailed use-of-force policies for that purpose. Most policies include categorical levels of force, commonly referred to as force "continua," despite the fact that they are not actually continuous scales. These force continua bin specific actions into categories according to their severity, and the levels of the categories are generally described without reference to situational details. For example a level might be labeled as deadly force and refer to any action in nearly any situation that is likely to result in great bodily harm or death. Binning actions into these categorical levels of force is intended to provide a framework for decision-making, with which officers can act at a level of force that is "objectively reasonable" (Tennessee v. Garner, 471 U.S. 1, 1985).

If lay evaluations of force are not well aligned with law-enforcement policies, however, there may be serious disputes between public and police judgments of force appropriateness. To reduce the potential for conflict between police and the public, it is crucial to understand where and to what extent law enforcement policies and public opinion agree and disagree. Although there is some research focused on how lay observers evaluate instances of police violence (Jefferis, Butcher, \& Hanley, 2011; Gerber \& Jackson, 2017), very little research has experimentally studied the effects of beliefs about police legitimacy on evaluations of civilian resistance toward police. Instead, the focus of prior research has tended to be on police actions or on motivating civilian cooperation (Thompson \& Daniel Lee, 2004; Sunshine \& Tyler, 2003; Gerber \& Jackson, 2017). Relatedly, a general relationship between high police-legitimacy and reduced support for general vigilante violence has been demonstrated (Haas, de Keijser, \& Bruinsma, 2012; Jackson, Huq, Bradford, \& Tyler, 2013; Haas, de Keijser, \& Bruinsma, 2014), but the types of private violence measured in these studies consists exclusively of violence committed by citizens against other citizens, not against police. We are unaware of any previous research that has investigated the detailed correspondence of lay evaluations of force with the categorical structure used by law enforcement, or of any research on legitimacy modulating evaluations of a wide array of specific civilian reactions to police especially not in a manner that relates directly to the way actions are described in police training and policy. To fill these gaps, the present research provides a map of lay evaluations of actions that comprehensively span the force categories, and offers insight into how beliefs about police legitimacy affect judgments of civilian violence against police as well as police violence against civilians.

Importantly, we are not proposing specific hypotheses about the effect of legitimacy on judgment, and therefore the framework of hypothesis-testing is not appropriate for the current study. Instead, we are measuring whatever relationships are revealed by the data, and so we are utilizing 
Bayesian estimation as a means to understand and quantify the most credible relationships between our measured variables given the data that we observe. For example, among the relationships revealed by our data, we observe that the acceptability of civilian violence increases as officer action severity increases, even for participants who believe strongly in the legitimacy of police. We also observe an overall trend indicating that legitimacy beliefs in general have an equivalently strong effect on judgments about civilian violence against police as they do on judgments of police violence against civilians. Thus, the findings we report here provide novel information about the direction and magnitude of the effects of police-legitimacy beliefs on judgments of civilian and police actions across the entire severity range of force options.

\section{Police and civilian perspectives on use of force}

There are raging debates about whether force used by police is morally appropriate. Take, for example, the case of Terence Crutcher who was shot by Tulsa, Oklahoma police officer Betty Jo Shelby who believed Crutcher was reaching for a weapon when, in fact, he was unarmed (Salinger, 2016). Or the case of Daniel Shaver - an intoxicated but unarmed man who was shot by Mesa, Arizona police officer Phillip Brailsford while crying and begging officers "please do not shoot" (Friedersdorf, 2017a, 2017b). In both of these cases the officers (i.e., Shelby and Brailsford) were criminally prosecuted, but juries ultimately acquitted them of all charges. Nevertheless, these cases (and others like them) are extraordinarily tragic, and seem to many people — including the families of Crutcher and Shaver and protesters who rallied around them - to represent unnecessary and immoral levels of violence inflicted by police (Hogan, 2017; Friedersdorf, 2017a). On the other hand, consider the case of a female Chicago police officer whose face was repeatedly slammed into the pavement by a male suspect until she lost consciousness and "thought she was gonna die," but even in that moment resolved not to use her firearm "because she didn't want her family or department to go through the scrutiny the next day on the national news" (Gorner \& Dardick, 2016).

Or the recent mass shooting at Marjory Stoneman Douglass high school, during which multiple Broward County sheriff's deputies — including school resource deputy Scot Peterson — remained stationary outside the building for four to six minutes while Nikolas Cruz was actively murdering the students and teachers inside (Stewart, 2018). It is unknowable how many of the 17 people killed (or 17 others wounded) might have been saved from harm if the first responders on the scene had engaged Cruz immediately, but given that the entire shooting lasted nearly six minutes (Blinder \& Mazzei, 2018; Wikipedia Contributors, 2018), the number of victims would almost certainly have been reduced.

In all of the aforementioned cases, the facts lend themselves to relatively extreme and singular moral interpretations of either excessive or insufficient/negligent levels of force used by police. But, notably, even in these cases, there is considerable disagreement about whether the police acted appropriately; different members of the public (and even different law enforcement officers and agencies) have very different attitudes about what constitutes appropriate police use of force. In 


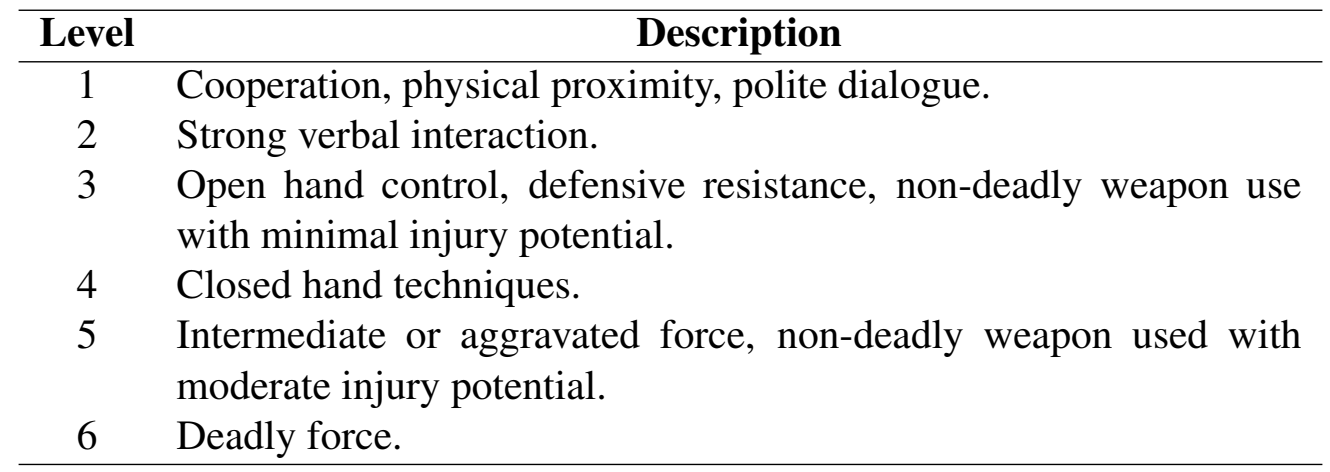

Table 1

Six ordinal levels of force (SOLOF) scale.

more ambiguous cases, where some of the facts on either side are more reasonable and uncertainty is amplified, this problem is exacerbated.

We point out these controversies regarding police use of force to emphasize a key premise: Public perceptions of police use of force often seem to be misaligned with law-enforcement implementations (and, ultimately, judicial/legal outcomes) of use of force. (If they did match, there wouldn't be such vociferous disputes.) On the one hand, law enforcement policies usually categorize forceful actions into discrete levels and agencies provide heuristics regarding which level of force is appropriate relative to the level of civilian resistance confronting officers. On the other hand, lay perceptions of the appropriateness of actions might be quite different than the organization and heuristics of official policies. Moreover, lay perceptions are likely to be modulated by relevant individual differences. Given the apparent conflict between public outrage and legal assessment of police use of force, research investigating how they align and diverge is crucial for maximizing police efficacy and public trust. In the next two sections, we describe law enforcement policies and some important individual differences among people.

\section{Six ordinal levels of force (SOLOF)}

At least $80 \%$ of law enforcement agencies use a list of rank-ordered force options as part of their official use-of-force policy (Terrill, Paoline, III, \& Ingram, 2011). These formal classifications provide guidance for how the officers employed at a given government agency are allowed to use force. Rank-ordered classifications of force are also prescribed within the social scientific literatures, where police and civilian actions are separated into distinct lists of role-specific categories (Terrill, Alpert, Dunham, \& Smith, 2003; Alpert \& Dunham, 2004). These lists are used to calculate the proportionality of police use of force relative to civilian resistance by quantifying a difference score, dubbed a "force factor". There is some evidence that this method for evaluating the reasonableness or excessiveness of force is reliable (Hickman, Atherley, Lowery, \& Alpert, 2015) and useful for professionals. 
Nearly three quarters of all law enforcement agencies use a 5 or 6 level classification (Terrill et al., 2011), and Terrill et al. (2003) recommend a six-category list for evaluation of police use of force and civilian resistance. Therefore, the current study used a six-category list shown in Table 1 and described more completely in the Method section. Because this type of force categorization is not actually continuous, we refer to this list as the six ordinal levels of force (SOLOF) scale (rather than using the common "force continuum" language). Notably, the descriptions of the levels in Table 1 do not specify contextual details such as location, time of day, or state of mind (e.g., intoxication). Instead, the levels are decontextualized because specifying all possible relevant contextual variables would be unwieldy and intractable, and also maximize correspondence with law enforcement continua which are also decontextualized.

\section{Individual differences: legitimacy beliefs}

A considerable amount of research has investigated the factors that influence public evaluations of police. Although salient demographic factors such as race (Johnson \& Kuhns, 2009) and gender (Chapman, 2012) do affect attitudes about police, the strongest and most salient individual difference that predicts disparate evaluations of police conduct are people's existing beliefs about police legitimacy (Tyler, 2006). That is, legitimacy beliefs seem to be the key individual difference to observe when measuring attitudes about the justness of police actions, including the use of force.

Beliefs about police legitimacy are driven by current and prior perceptions of police acting in a procedurally just manner (e.g., behaving respectfully toward citizens and allowing them to voice their perspective) (Mazerolle, Antrobus, Bennett, \& Tyler, 2013), and these perceptions are grounded in the social context to which evaluators are or have been exposed (Braga, Winship, Tyler, Fagan, \& Meares, 2014). Legitimacy beliefs include at least two subcomponents (Gerber \& Jackson, 2017): (1) felt obligation, which is the degree to which a person feels obligated to obey the police; and (2) norm alignment, which is the extent to which a person believes that their own values align with the values of the police. These two dimensions are drawn from a theoretical conceptualization of the fundamental legitimacy of authority that is rooted in a process-based model of procedural justice (Tyler, 2006; Hamm, Trinkner, \& Carr, 2017). This model prioritizes perceptions of fairness over outcome-driven evaluations as the primary predictor of legitimacy beliefs, and posits that the extent to which citizens' values align with those in authority (i.e., norm alignment) and the extent to which they grant authority figures the ability to dictate acceptable behavior (i.e., felt obligation) together comprise individual perceptions of fairness and, thus, of the legitimacy or illegitimacy of authority figures, including police.

\section{Assaying lay perceptions of specific forceful actions}

In the present research, we generated a list of specific actions for each of the SOLOF levels. These actions could be performed by either a police officer or a civilian with whom the officer was interacting-a framework that corresponds to the reality of how violence often emerges in police- 
civilian encounters. Lay participants rated the morality and physical severity of police or civilian actions when performed in response to an action by the other party. Trends in ratings were captured by regression models that predicted ratings as a function of the actions and the rater's legitimacy beliefs, gender, race, and political affiliation.

\section{Method}

\section{Participants}

To maximize the diversity and generalizability of our sample, we collected data from the Indiana University (IU) undergraduate subject pool in the Department of Psychological and Brain Sciences and from Amazon Mechanical Turk (MTurk). Analyses were initially run separately for the IU and MTurk samples, and then combined after we observed that the model descriptions for each sample were virtually identical. Supplementary material presents the separate analyses (https://osf.io/aqfeh).

We recruited 411 MTurk participants and 395 IU subject pool participants, all of whom completed the study through a web browser. Participation requirements constrained participation to individuals residing in the United States who were 18 or older at the time of participation and who were fluent in English. Although we set up MTurk requirements to disallow non-US participation, we also recorded geolocation information associated with the Internet Protocol addresses used by participants, and subsequently excluded 38 MTurk participants for participating from outside the US. We excluded participants who missed more than one of the 11 attention checks. We also excluded participants who had a mean absolute deviation (MAD) in their ratings that was more than three standard deviations below the mean MAD of all participants because very small MAD probably indicates leaving the response slider at its default level for most trials. This data cleaning procedure resulted in a final $\mathrm{N}$ of 350 MTurk participants and 317 IU subject pool participants. The combined total $\mathrm{N}$ was 667 .

A demographic breakdown of our 667 participants, according to the categories they selected on the questionnaire at the conclusion of the experiment, included 404 females, 261 males, and 2 participants who selected other. There were 3 American Indian/Alaska Native participants, 71 Asian participants, 54 Black or African American participants, 32 Hispanic or Latino participants, 486 White participants, 19 participants who selected More than one, and 2 participants who selected Unknown.

\section{Design}

Using a combined version of Terrill et al. (2003)'s separated civilian resistance and officer force levels, we constructed a list of forceful actions that could reasonably be performed by either an officer or a civilian. We then selected 22 representative actions from this list, ensuring that at least three actions were located, a priori, in each of the six SOLOF categories. In addition to this primary goal of choosing broadly representative actions, we also tried to choose actions that were diverse 


\begin{tabular}{|c|c|}
\hline $\begin{array}{c}\text { SOLOF } \\
\text { Level }\end{array}$ & Action Statement \\
\hline \multirow{3}{*}{1} & the [officer/civilian] stood near the [civilian/officer] \\
\hline & the [officer/civilian] asked the [civilian/officer] how he was doing \\
\hline & the [officer/civilian] waved at the [civilian/officer] in greeting \\
\hline \multirow{4}{*}{2} & the [officer/civilian] yelled "get back" at the [civilian/officer] \\
\hline & $\begin{array}{l}\text { the [officer/civilian] shouted "get your fucking hands up!" / "I don't have to fucking listen to } \\
\text { you!" at the [civilian/officer] }\end{array}$ \\
\hline & the [officer/civilian] said "if you touch me, you're gonna get hurt" to the [civilian/officer] \\
\hline & the [officer/civilian] called the [civilian/officer] a "thug" / "pig" \\
\hline \multirow{4}{*}{3} & the [officer/civilian] put handcuffs on/pulled away from the [civilian/officer] \\
\hline & the [officer/civilian] sprayed the [civilian/officer] with pepper spray \\
\hline & the [officer/civilian] shocked the [civilian/officer] with a tazer \\
\hline & the [officer/civilian] twisted the arm of the [civilian/officer], forcing him to the ground \\
\hline \multirow{4}{*}{4} & the [officer/civilian] punched the [civilian/officer] in the face \\
\hline & the [officer/civilian] kicked the [civilian/officer] in the stomach \\
\hline & the [officer/civilian] applied a chokehold to the [civilian/officer] \\
\hline & the [officer/civilian] headbutted the [civilian/officer] in the face \\
\hline \multirow{3}{*}{5} & the [officer/civilian] struck the [civilian/officer] on the leg with a collapsible baton/metal pipe \\
\hline & $\begin{array}{l}\text { the [officer/civilian] shot/struck the [civilian/officer] in the chest with a beanbag shotgun } \\
\text { round/baseball bat }\end{array}$ \\
\hline & the [officer/civilian] struck the [civilian/officer] in the stomach with a metal flashlight \\
\hline \multirow{4}{*}{6} & the [officer/civilian] shot the [civilian/officer] in the chest with a handgun \\
\hline & the [officer/civilian] shot the [civilian/officer] in the head with a handgun \\
\hline & the [officer/civilian] struck the [civilian/officer] with a motor vehicle \\
\hline & the [officer/civilian] slammed the [civilian/officer]'s head into the concrete curb \\
\hline
\end{tabular}

Figure 1. Actions with their a priori SOLOF severity level from Table 1. Colors in SOLOF column correspond to colors used in subsequent plots. Reprinted with permission (pending) from Figure 1 of Celestin and Kruschke (2019). 
and realistic. These actions were presented de-contextualized (i) to match the de-contextualized nature of the SOLOF levels and (ii) because specifying contextual details would introduce myriad additional factors. Seventeen of the actions were exactly the same for the officer and civilian, while 5 of the actions were unique for those roles to ensure that they seemed plausible for a civilian or officer but were rationally matched in terms of severity. For example, the officer action of handcuffing was not performed by the civilian because it seems implausible that a civilian would handcuff an officer. Instead, the action of pulling away was matched with handcuffing and assigned exclusively to the civilian. Figure 1 displays all of the actions and the SOLOF category in which we located them.

The current study employed a partially-crossed within-subjects design that randomly permuted the separate lists of officer and civilian actions and then paired them together. Eleven pairs were assigned to the "civilian" condition, in which the civilian action occurred second and was the focus of the ratings, while the remaining 11 actions were assigned to the "officer" condition in which the officer action occurred second and was the focus of the ratings. The officer and civilian trials were randomly interspersed. This method assured that in only 22 pairs of actions every participant saw all of the officer and civilian actions (providing ratings of 11 civilian actions and 11 officer actions).

\section{Procedure}

Participants gave informed consent to take part in the study and were shown the following instructions:

"On the following screens, you will be presented with scenarios that represent real life interactions involving police officers and civilians. Officer and civilian names have been purposefully excluded. For each scenario, you will be presented with a pair of actions that occurred during the encounter. Each action pair will include one action by the officer and one action by the civilian, though other actions may have occurred before, between, or after the two actions that are listed. The order in which the presented actions occurred during the encounter is the order in which they are listed. It is very important that you read each action description carefully, because the actions will change for each scenario."

"You will be asked to make several ratings of some of the actions. You will always be asked to rate the second action listed, but the specific actions and the order of the questions will change between scenarios, so it is very important that you read each question carefully prior to responding."

Participants were also instructed about the four rating questions (see details below) and pairs of officer and civilian actions. We emphasized that the order in which the actions occurred was the order in which they were presented to mitigate a potential confound of action order that might arise if action order was ambiguous. Order alone clearly matters for moral inference (Schwitzgebel \& Cushman, 2012). And it seems reasonable for participants to infer that whoever acts first in our 


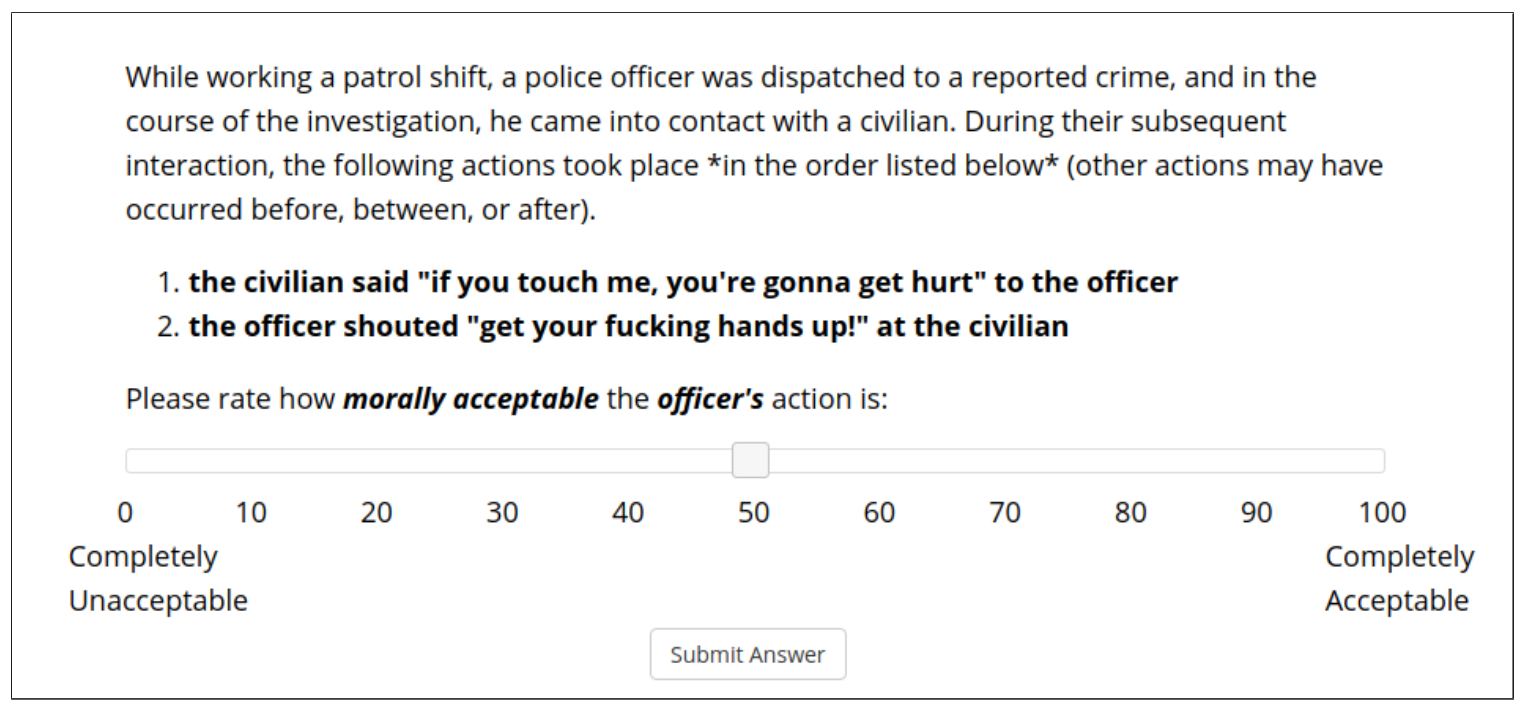

Figure 2. Example screenshot from the experiment.

scenario is initiating aggression and likely more blameworthy as a moral agent, while whoever acts subsequently is responding as a moral patient (Schein \& Gray, 2017). The nature of the officer role potentially complicates this dynamic, because a participant (especially one with high levels of trust in police) might assume that police officers are always (or nearly always) responding to some prior violent act or threat, even if it isn't explicitly mentioned. Citizens, on the other hand, do not have any such intrinsic benefit of the doubt, because the category of "citizen" is very general and does not describe a set of professional responsibilities that include the legitimate use of violence. For this reason, we always inquired about the second action which was explicitly preceded by an action from the other role. Thus, ratings were always of "reactions" to the other party, to be sure there was no confounding of actor role (civilian vs officer) with action order (action vs reaction).

Within each action rating trial, participants read a short vignette as shown in the screen shot of Figure 2. As can be seen in both, actions were displayed as bulleted points which were emphasized using bold font. The key word in every rating question was also displayed in bold font. The rating questions were presented one at a time in random order, and participants made each rating by adjusting the location of a slider on a bar spanning the range of 0 to 100 . The rating questions and their semantic anchors are listed below:

- Please rate how much force is involved in the officer's/civilian's action: $(0=$ No Force, 100 = Maximum Force)

- Please rate how morally acceptable the officer's/civilian's action is: ( $0=$ Completely Unacceptable, $100=$ Completely Acceptable)

- Please rate the extent to which the officer/civilian used an appropriate level of force $(0=$ Insufficient, $50=$ Appropriate, $100=$ Excessive) 
- Please rate the extent to which the officer/civilian should be punished for his action: $(0=$ Not at all, $100=$ Severely)

In order to ensure thoughtful responding and to provide a mechanism by which to exclude participants who were not engaged in the task, 11 attention checks were inserted in random places in the sequence for some action pairs. Each attentiveness question explicitly advised participants to move the slider to the leftmost or rightmost position on the scale.

Following the action rating trials, participants answered six, randomly ordered questions measuring the two subcomponents of police legitimacy beliefs (Gerber \& Jackson, 2017) which are (1) felt obligation: the extent to which someone believes they should obey police, and (2) norm alignment: the extent to which someone believes that their own values overlap those of the police. The specific questions capturing these two dimensions were as follows:

- Felt Obligation

- You should support the decisions made by police officers even when you disagree with them.

- You should do what the police tell you even if you do not understand or agree with the reasons.

- You should do what the police tell you to do even if you do not like how they treat you.

- Norm Alignment

- The police generally have the same sense of right and wrong that you do.

- The police stand up for values that are important to you.

- You and the police want the same things for your community.

Each of these legitimacy questions was answered by adjusting a slider ranging from 0 ("completely disagree") to 100 (completely agree).

Participants also answered yes/no questions measuring personal or vicarious negative experiences with police (Weitzer, 2005):

- Personal

- Have you ever been stopped by police on the street without good reason?

- Have the police ever used insulting language toward you?

- Have you ever seen a police officer engage in any corrupt activities (e.g., taking bribes or involvement in drug trade)?

- Have police ever used excessive force against you?

- Vicarious 
- Have the police ever used insulting language toward anyone else in your household?

- Have police ever used excessive force against anyone else in your household?

- Has anyone else in your household ever been stopped on the street by police without good reason?

In subsequent data analyses we considered regression models that used the negative-experience answers as covariates, but ultimately found that they were not particularly useful. See discussion of the models below for further information and see also the supplementary materials (https:// osf.io/aqfeh) for specific results that include these variables.

The experiment concluded with a series of demographic questions including race and gender, as well as a single item measure of political affiliation (Iyer, Koleva, Graham, Ditto, \& Haidt, 2012), and a debriefing.

The experiment interface was programmed using JavaScript, html, and CSS, as well as the libraries available in the jsPsych package (de Leeuw, 2015). We employed either a psiTurk (Gureckis et al., 2015) or Apache server alongside a SQL database and PHP scripts to run the experiment and save the data. Additionally, all data cleaning, pre-processing, and analyses were conducted via the R programming language, RStudio (Team, 2016), JAGS (Plummer, 2003), and Stan (Stan Development Team, 2016), and with programs adapted from Kruschke (2015).

\section{Results}

\section{Data transformation and regression model}

Recall that our dependent variables include ratings of acceptability, excessiveness, punishment, and force, and that these ratings were all made using a slider that ranged from 0 to 100 . Examining the raw distributions of each of these ratings revealed that a notable proportion of the ratings piled at both ends of the scale, and the other ratings tended to form a unimodal distribution that was skewed toward the middle. Therefore, we treated any response more extreme than 5 or 95 as censored, meaning its value is not modeled as the specific slider value but is instead modeled as an unknown value at least as extreme as 5 or 95 , respectively. To approximately normalize the uncensored data, we logit transformed all of the ratings (after dividing by 100).

A key independent variable was participants' beliefs in police legitimacy as measured by their ratings of felt obligation (FO) and norm alignment (NA). FO and NA ratings were highly reliable and strongly correlated. Specifically, the three items for FO had a Cronbach's $\alpha=0.82$, the three items comprising NA had $\alpha=0.87$, and all six items together had $\alpha=0.87$. The correlation between the combined FO and combined NA items was $\rho=0.61$. Because all of the items were so strongly related, the three questions measuring felt obligation were averaged together, as were the three questions measuring norm alignment. These averaged ratings were then standardized. Finally, the two standardized ratings were averaged together to form one composite individual difference measure of police legitimacy beliefs, denoted $\ell$. Notice that this legitimacy score is inherently 
standardized, which implies that the mean $\ell$ is zero and that most values of $\ell$ fall between -2.0 and +2.0 .

Because we are not proposing specific hypotheses about how legitimacy beliefs affect moral judgments, we cannot appropriately conduct traditional frequentist hypothesis tests. Rather, our goal was to precisely measure the relationships (if any) between civilian and officer action severity and their interaction (if any) with legitimacy beliefs. Thus, taking a Bayesian approach that explicitly quantifies the credibility and uncertainty of the parameter values in our models is the best approach to accomplish our goals in precisely describing the present data.

We constructed Bayesian linear regression models for each of the rating questions. Ratings were described as a weighted combination of civilian action severity, officer action severity, and legitimacy beliefs (i.e., $\ell$ ), along with selected interactions. The severity of the officer and civilian actions were simultaneously estimated, yielding latent moral and physical severity scales for the entire set of actions. These scale estimates are described in detail in a previous report (Celestin \& Kruschke, 2019), and the focus of the present report is the regression coefficients and corresponding trends in the ratings.

The regression model is expressed formally as

$$
\begin{aligned}
\hat{y}_{q, c, f} & =\underbrace{\left(\beta_{0, q}+\beta_{3, q} \cdot \ell\right)}_{\text {baseline }}+\underbrace{\left(\beta_{1, q}+\beta_{4, q} \cdot \ell\right)}_{\text {influence of civilian action }} \cdot \overbrace{\gamma_{c}}^{\text {civilian action severity }}+\underbrace{\left(\beta_{2, q}+\beta_{5, q} \cdot \ell\right)}_{\text {influence of officer action }} \cdot \overbrace{\chi_{f}}^{\text {officer action severity }}+\underbrace{\beta_{6, q} \cdot \gamma_{c} \cdot \chi_{f}}_{\text {civilian } \times \text { officer interaction }} \\
& =\beta_{0, q}+\beta_{1, q} \cdot \gamma_{c}+\beta_{2, q} \cdot \chi_{f}+\beta_{3, q} \cdot \ell+\beta_{4, q} \cdot \ell \cdot \gamma_{c}+\beta_{5, q} \cdot \ell \cdot \chi_{f}+\beta_{6, q} \cdot \gamma_{c} \cdot \chi_{f}
\end{aligned}
$$

where $\hat{y}$ represents the predicted value of a rating (logit transformed), $q$ indexes the rating question (1-8, i.e., the four types of ratings of both officer and civilian actions), $c$ indexes the civilian action $(1-22), f$ indexes the officer action (1-22), $\ell$ denotes the participant's legitimacy beliefs, $\gamma$ denotes the estimated civilian-action scale value, and $\chi$ denotes the estimated officer-action scale value. Each of the $\beta$ variables is an estimated regression coefficient. Equation (2) arranges the terms in a traditional form that accentuates multiplicative interaction terms, while Equation (1) arranges the terms to emphasize the conceptual framework of the model: A rating is generated from a baseline plus a weighted influence of the civilian action plus a weighted influence of the officer action, with the weightings and baseline modulated by the legitimacy beliefs $(\ell)$ of the participant, and by the interaction of civilian and officer action severities.

To aid interpretation of Equation (1), consider rating the acceptability of officer actions, so $\hat{y}$ is the predicted acceptability rating. Intuitively, as officer actions $\chi_{f}$ become more severe, their acceptability should decline, and so the coefficient $\beta_{2}$ should be negative. The magnitude of this decline might be modulated by the respondent's legitimacy beliefs $\ell$ : it might be the case that respondents with high $\ell$ would be more accepting of severe officer actions, meaning that coefficient $\beta_{5}$ might be positive. Analogously, as civilian actions $\gamma_{c}$ become more severe, the acceptability of severe officer actions should increase, meaning that coefficient $\beta_{1}$ should be positive. It might be 
the case that respondents with high legitimacy beliefs $\ell$ should be more sensitive to civilian action severity, meaning that coefficient $\beta_{4}$ might be positive. Additionally, the rate at which officer action acceptability declines as officer action severity increases should be greater for low severity civilian actions than it is for high severity civilian actions. That is, intuitively, officer acceptability should decrease less rapidly when the civilian action is very severe compared to when it is not severe, meaning that coefficient $\beta_{6}$ should be positive. Finally, the baseline acceptability is established by the intercept, $\beta_{0}$, which might be higher for respondents with higher legitimacy beliefs $\ell$, that is, coefficient $\beta_{3}$ might be positive.

The ratings for moral evaluations (i.e., acceptability, appropriateness, and punishability) were modeled together using the same estimated latent scale values for the actions, but separately from the ratings for physical evaluations (i.e., force) which had its own estimated latent scale values for the actions. This separation was made a priori because we assumed that the scale value for the physical force of an action might be quite different than the scale value for the moral severity of an action. Estimated scale values are discussed at length in Celestin and Kruschke (2019).

We made the conventional assumption that ratings were normally distributed around the predicted value in Equation 1, with distinct standard deviation $\sigma_{q}$ for each type of question. The data were reasonably normal because of our logit transformation and censoring.

Several variations of the model were also considered. In one variation, we added negative experience with police as a predictor, including an interaction term for both officer and civilian actions. In another variation, we removed legitimacy beliefs $\ell$ as a predictor and replaced it with negative experience with police, again including interaction terms. In yet another variation, we added participant sex, race, and political affiliation, as well as negative experiences with police as predictors. All of these models yielded estimates that reflected weak or non-existent effects and showed increased uncertainty in the parameter estimates as a result of including additional predictors. Moreover, any effects that were present were unreliable across dependent measures. For these reasons, we are not confident that any effects observed for these additional individual difference measures represent meaningful effects in reality. Importantly, the inclusion of these additional predictors did not substantively alter the conclusions we present here. Thus, the analyses we present reflect the model of Equation 1. However, see the supplementary materials (https: / / osf.io/aqfeh) for additional results from the model variations.

Bayesian Methods. We used Bayesian methods to estimate the parameters (Kruschke, 2015; Kruschke \& Liddell, 2018a, 2018b). Bayesian analysis produces a joint probability distribution across all the model parameters, including all regression coefficients and latent scale values. This probability distribution is called a "posterior" distribution because it represents the credibilities of parameter values after taking the data into account. The posterior distribution on a parameter is summarized by its most probable value (i.e., its mode) and the interval that spans the $95 \%$ most probable values, referred to as the 95\% highest density intervals (HDI). The width of an HDI represents the uncertainty of the parameter's estimate, so smaller HDIs reflect greater precision.

A unique element of Bayesian analysis is that it requires establishing prior probability distri- 
butions for every estimated parameter. We chose priors which were diffuse in relation to the scale of the data, ensuring that our prior choices had very little influence on the posterior estimates.

We coded and calculated all of our models using the programming language $\mathrm{R}$ and JAGS software (Plummer, 2003) via the runjags package (Denwood, 2016). All MCMC chains exhibited convergence, and the effective sample size for our parameter chains approaches 10,000.

\section{Estimates of regression coefficients}

The modal posterior estimates for all of the regression coefficients, and their 95\% HDIs, are presented in Table 2. As an example, recall from our previous discussion after introducing Equation 1 that intuition suggests the coefficient $\beta_{2}$ for acceptability of officer action should be negative because the acceptability of actions should decline as their severity goes up. Table 2 shows that the estimated value of $\beta_{2}$ for acceptability of officer actions is in fact strongly negative. The value of the coefficient is how much the predicted rating changes (on the logit transformed scale) when the action severity changes by one unit on its scale anchored at 1.0 for the least severe action and 6.0 for the most severe action. Graphical representations of the coefficients are presented in the following sections.

[Blank space intentionally inserted for readability of subsequent sections.] 


\begin{tabular}{|c|c|c|}
\hline Parameter & Question & Posterior Mode (95\% HDI) \\
\hline$\beta_{0}$ & punish, officer action & $-1.57(-1.74,-1.41)$ \\
\hline$\beta_{1}$ & punish, officer action & $-1.13(-1.19,-1.07)$ \\
\hline$\beta_{2}$ & punish, officer action & $1.59(1.52,1.67)$ \\
\hline$\beta_{3}$ & punish, officer action & $-0.51(-0.58,-0.44)$ \\
\hline$\beta_{4}$ & punish, officer action & $0.01(-0.04,0.06)$ \\
\hline$\beta_{5}$ & punish, officer action & $-0.03(-0.08,0.03)$ \\
\hline$\beta_{6}$ & punish, officer action & $-0.28(-0.32,-0.25)$ \\
\hline$\sigma$ & punish, officer action & $2.31(2.25,2.37)$ \\
\hline$\beta_{0}$ & acceptable, officer action & $0.45(0.30,0.61)$ \\
\hline$\beta_{1}$ & acceptable, officer action & $1.21(1.14,1.27)$ \\
\hline$\beta_{2}$ & acceptable, officer action & $-1.38(-1.45,-1.30)$ \\
\hline$\beta_{3}$ & acceptable, officer action & $0.50(0.42,0.57)$ \\
\hline$\beta_{4}$ & acceptable, officer action & $0.04(-0.02,0.09)$ \\
\hline$\beta_{5}$ & acceptable, officer action & $0.05(0.00,0.10)$ \\
\hline$\beta_{6}$ & acceptable, officer action & $0.41(0.36,0.45)$ \\
\hline$\sigma$ & acceptable, officer action & $2.54(2.48,2.60)$ \\
\hline$\beta_{0}$ & appropriate, officer action & $0.42(0.34,0.49)$ \\
\hline$\beta_{1}$ & appropriate, officer action & $-0.53(-0.56,-0.5)$ \\
\hline$\beta_{2}$ & appropriate, officer action & $0.69(0.66,0.73)$ \\
\hline$\beta_{3}$ & appropriate, officer action & $-0.07(-0.11,-0.03)$ \\
\hline$\beta_{4}$ & appropriate, officer action & $-0.03(-0.05,0.01)$ \\
\hline$\beta_{5}$ & appropriate, officer action & $0.06(0.03,0.09)$ \\
\hline$\beta_{6}$ & appropriate, officer action & $0.02(0,0.04)$ \\
\hline$\sigma$ & appropriate, officer action & $1.58(1.55,1.62)$ \\
\hline$\beta_{0}$ & force, officer action & $0.06(-0.09,0.21)$ \\
\hline$\beta_{1}$ & force, officer action & $-0.22(-0.25,-0.2)$ \\
\hline$\beta_{2}$ & force, officer action & $1.6(1.54,1.67)$ \\
\hline$\beta_{3}$ & force, officer action & $-0.09(-0.13,-0.05)$ \\
\hline$\beta_{4}$ & force, officer action & $0.04(0.01,0.06)$ \\
\hline$\beta_{5}$ & force, officer action & $0.08(0.05,0.11)$ \\
\hline$\beta_{6}$ & force, officer action & $-0.02(-0.04,0)$ \\
\hline$\sigma$ & force, officer action & $1.35(1.32,1.38)$ \\
\hline$\beta_{0}$ & punish, civilian action & $-0.86(-0.98,-0.73)$ \\
\hline$\beta_{1}$ & punish, civilian action & $1.72(1.67,1.78)$ \\
\hline$\beta_{2}$ & punish, civilian action & $-0.43(-0.46,-0.39)$ \\
\hline$\beta_{3}$ & punish, civilian action & $0.38(0.33,0.44)$ \\
\hline$\beta_{4}$ & punish, civilian action & $0.11(0.07,0.16)$ \\
\hline$\beta_{5}$ & punish, civilian action & $0.08(0.04,0.11)$ \\
\hline$\beta_{6}$ & punish, civilian action & $-0.12(-0.15,-0.09)$ \\
\hline$\sigma$ & punish, civilian action & $1.7(1.66,1.74)$ \\
\hline$\beta_{0}$ & acceptable, civilian action & $-0.29(-0.42,-0.17)$ \\
\hline$\beta_{1}$ & acceptable, civilian action & $-1.56(-1.63,-1.51)$ \\
\hline$\beta_{2}$ & acceptable, civilian action & $0.62(0.57,0.66)$ \\
\hline$\beta_{3}$ & acceptable, civilian action & $-0.51(-0.58,-0.45)$ \\
\hline$\beta_{4}$ & acceptable, civilian action & $-0.15(-0.2,-0.11)$ \\
\hline$\beta_{5}$ & acceptable, civilian action & $-0.03(-0.07,0.01)$ \\
\hline$\beta_{6}$ & acceptable, civilian action & $0.21(0.18,0.25)$ \\
\hline$\sigma$ & acceptable, civilian action & $2.13(2.08,2.18)$ \\
\hline$\beta_{0}$ & appropriate, civilian action & $0.49(0.42,0.56)$ \\
\hline$\beta_{1}$ & appropriate, civilian action & $0.69(0.66,0.73)$ \\
\hline$\beta_{2}$ & appropriate, civilian action & $-0.33(-0.36,-0.3)$ \\
\hline$\beta_{3}$ & appropriate, civilian action & $0.22(0.17,0.27)$ \\
\hline$\beta_{4}$ & appropriate, civilian action & $0.08(0.05,0.12)$ \\
\hline$\beta_{5}$ & appropriate, civilian action & $0.03(0,0.07)$ \\
\hline$\beta_{6}$ & appropriate, civilian action & $-0.02(-0.04,0.01)$ \\
\hline$\sigma$ & appropriate, civilian action & $1.8(1.77,1.84)$ \\
\hline$\beta_{0}$ & force, civilian action & $-0.19(-0.33,-0.04)$ \\
\hline$\beta_{1}$ & force, civilian action & $1.58(1.52,1.64)$ \\
\hline$\beta_{2}$ & force, civilian action & $-0.15(-0.18,-0.13)$ \\
\hline$\beta_{3}$ & force, civilian action & $0.05(0.01,0.09)$ \\
\hline$\beta_{4}$ & force, civilian action & $0.12(0.09,0.15)$ \\
\hline$\beta_{5}$ & force, civilian action & $0.04(0.01,0.07)$ \\
\hline$\beta_{6}$ & force, civilian action & $-0.02(-0.04,0)$ \\
\hline$\sigma$ & force, civilian action & $1.36(1.33,1.39)$ \\
\hline
\end{tabular}

Table 2

Parameter estimates for the regression model of Equation 1. HDI = highest density interval. 

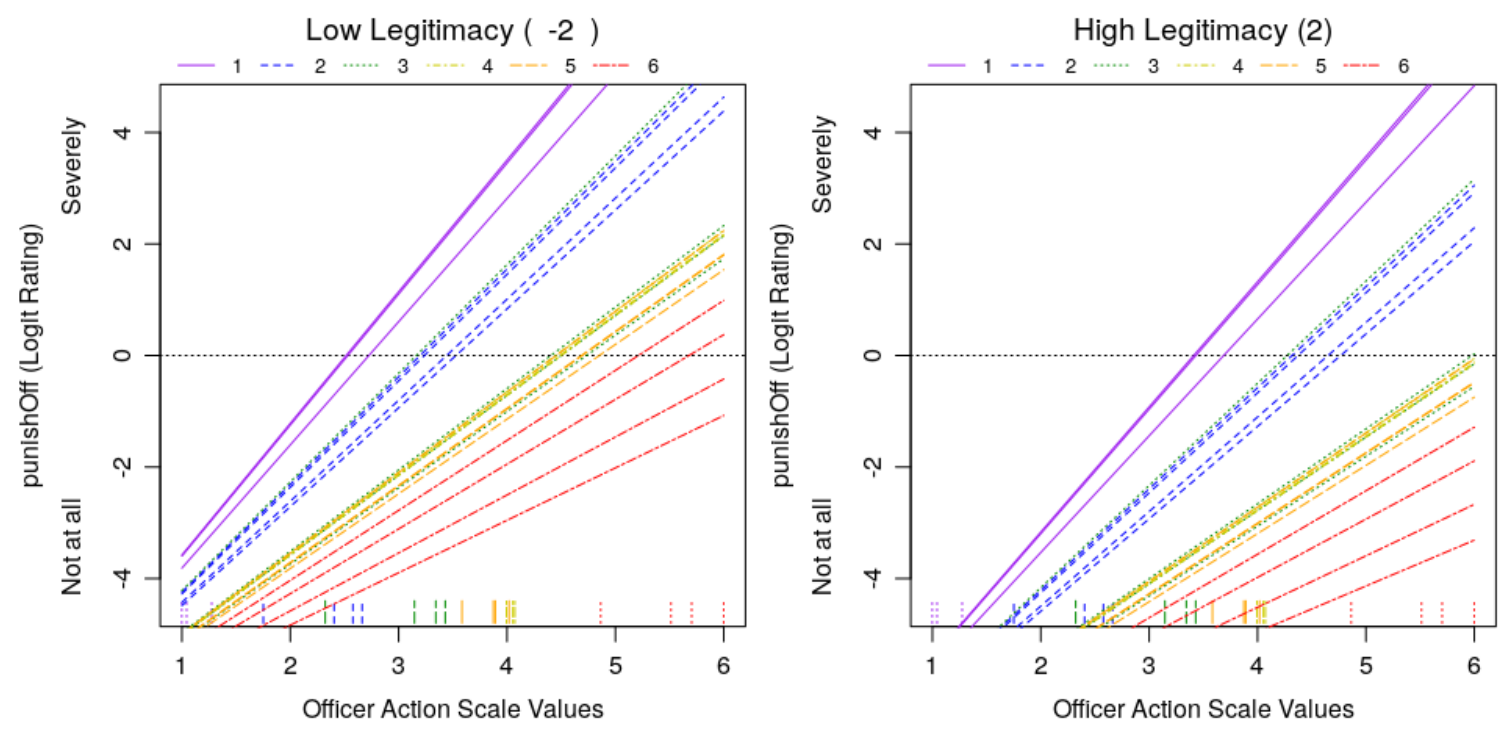

Figure 3. Regression model trend lines for officer punishment ratings. punishOff = punishability rating of officer action. The Low Legitimacy panel plots model trends for participants 2 standard deviations (SDs) below the mean legitimacy score, and the High Legitimacy panel 2 SDs above. In each panel, the vertical axis is the logit transformed rating, where 0 on the logit transformed scale corresponds to 50 on the original rating scale, and -4 and +4 on the transformed scale correspond to approximately 2 and 98 , respectively, on the original rating scale. The horizontal axis is the latent action severity, where 1.0 is anchored at the least severe action and 6.0 is anchored at the most severe action. The "rug plot" along the horizontal axis (i.e., the small vertical lines) indicates the estimated scale values of the 22 officer actions (i.e., modal posterior $\chi$ from Eq. 1, reported in Celestin \& Kruschke, 2019), with their SOLOF categories coded by color and line type. The main body of the panels plot a separate line for each civilian action.

Officer punishment ratings. The model's trend lines for officer punishment are plotted in Figure 3. There are two panels in Figure 3, with the left panel showing model trend for participants with very low legitimacy belief $(\ell=-2)$ and the right panel showing model trend for participants with very high legitimacy belief $(\ell=+2)$.

The trend lines in Figure 3 show the punishability of officer actions. Notice that the lines go up, indicating that punishability increases as officer action severity increases. The slope of the lines is the slope coefficient on officer-action severity from Equation 1 , namely $\beta_{2}+\beta_{5} \cdot \ell+\beta_{6} \cdot \gamma \cdot \chi$, using $\ell=-2$ in the left panel and $\ell=+2$ in the right panel. Table 2 shows that $\beta_{2}$ for punishability of officer action is indeed positive, with a posterior mode of +1.59 (and 95\% HDI from 1.52 to 1.67). Table 2 shows that $\beta_{5}$ for punishability of officer action had a posterior mode of nearly zero (with an HDI including zero), which means that the slope for punishability is essentially unaffected by a participant's legitimacy belief, and therefore the slopes of the lines in the two panels of Figure 3 are 
visually very similar. However, the interaction between civilian and officer action severity indicated by regression coefficient $\beta_{6}$ had a negative posterior mode of -0.28 (and 95\% HDI from -0.32 to $-0.25)$. This indicates that the rate at which officer punishment increases as officer action severity increases, changes (i.e., decreases) as civilian action severity increases. This interaction is visible in both panels of Figure 3 by observing that the slope of low-severity civilian actions is much steeper than the slope of high-severity civilian actions, that is, the lines "fan out".

In Figure 3 there is a separate line for each civilian action, and the intercept of each line is given by Equation 1 as $\left(\beta_{0, q}+\beta_{3} \cdot \ell\right)+\left(\beta_{1}+\beta_{4} \cdot \ell\right) \cdot \gamma$ where $\gamma$ is the latent severity of the civilian action (for discussion of the values of $\gamma$ see Celestin $\&$ Kruschke, 2019). Intuitively, as a civilian action becomes more severe, any specific officer reaction should be less punishable, suggesting that $\beta_{1}$ should be negative. Indeed, Table 2 shows that $\beta_{1}$ had a posterior mode of -1.13 (with $95 \%$ HDI from -1.19 to -1.07 ). The large magnitude of $\beta_{1}$ is represented visually in Figure 3 by the large spread between the lines. Note that the highest lines are the least severe civilian actions (hence an officer re-action is more punishable) and the lowest lines are the most severe civilian actions (hence an officer re-action is less punishable).

Visually comparing the two panels of Figure 3 suggests that the main influence of legitimacy beliefs is the overall rating of punishability; that is, the lines in the $\ell=-2$ panel are higher than the lines in the $\ell=+2$ panel. In other words, participants with very low legitimacy beliefs tended to rate officer actions as much more punishable than participants with very high legitimacy beliefs. The regression coefficient that controls the overall level as a function of $\ell$ is $\beta_{3}$, which had a posterior mode of -0.51 (with $95 \%$ HDI from -0.58 to -0.44 ). In particular, notice that when officer actions are most severe, the lines in the $\ell=-2$ panel representing all of the physical but non-lethal actions, as well as two of the lethal action lines, fall above the 0 midpoint. In contrast, all of the physical but non-lethal and the lethal action lines fall below the midpoint in in the $\ell=+2$ panel.

These results provide new evidence for a direct link between legitimacy beliefs and the magnitude of punishment evaluations of police officers who are using force, which is a novel finding given that prior research only assesses action approval (Gerber \& Jackson, 2017)., but not other measures of moral judgment such as punishment. Our results show that people who view the police as less legitimate favor increased punishment for forceful actions relative to people with higher legitimacy beliefs who allow police more leniency, and this relationship holds across all levels of force severity.

Officer acceptability ratings. Acceptability ratings for officer actions showed an inverse pattern relative to punishment. This makes intuitive sense, as more punishable actions should be less acceptable. The trend lines for acceptability of officer action are plotted in Figure 4. Acceptability declines as action severity increases; the coefficient $\beta_{2}$ had a posterior mode of -1.20 (with $95 \%$ HDI from -1.27 to -1.14 ). The decline is virtually unaffected by legitimacy beliefs as coefficient $\beta_{5}$ is very near zero (with an HDI including zero), meaning that the slopes of the lines are nearly the same in the two panels of Figure 4. However, the interaction between civilian and officer action severity controlled by regression coefficient $\beta_{6}$ had a positive posterior mode of 0.41 (and 

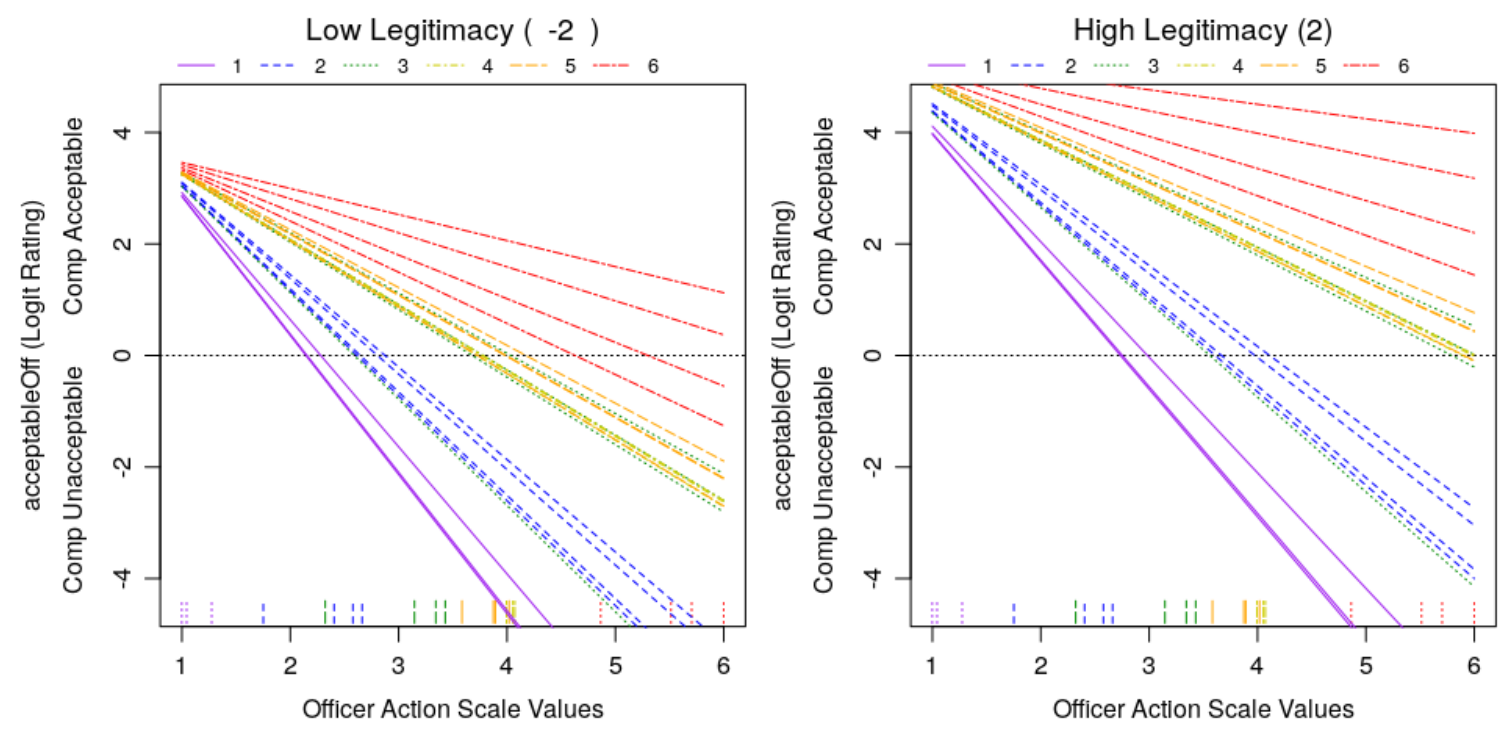

Figure 4. Regression model trend lines for officer acceptability ratings. acceptableOff $=$ acceptability rating of officer action. Comp $=$ completely. See Figure 3 for a detailed description of the figure components.

95\% HDI from 0.36 to 0.45 ). This indicates that as civilian action severity increases, acceptability judgments of officer actions decrease less steeply when officer actions become more severe. This interaction is visible in both panels of Figure 3 by observing that the slope of low-severity civilian actions (i.e., the purple solid lines) is much steeper than the slope of high-severity civilian actions (i.e., the red dot-dash lines).

Acceptability of officer reactions increased with the severity of the preceding civilian action. This can be seen in Figure 4 as the spread between the lines representing different civilian actions, with the solid (purple) lines for mild actions well below the dash-dot (red) lines of lethal actions. The regression coefficient $\beta_{1}$ had a posterior mode of 1.21 (with 95\% HDI from 1.14 to 1.27). The regression coefficient $\beta_{4}$ was nearly zero, meaning that the effect of civilian action was similar across the range of legitimacy beliefs.

The primary influence of legitimacy can be seen in the overall height of the lines across panels: acceptability of officer action tends to be higher for high legitimacy than for low legitimacy. The regression coefficient $\beta_{3}$ had a posterior mode of 0.50 (with 95\% HDI from 0.42 to 0.57 ) indicating that rated acceptability of officers increased as legitimacy $\ell$ increased.

Notice in the left panel of Figure 4, for participants with very low legitimacy beliefs, officer actions at SOLOF level 6 (above 5.0 on the latent severity scale) are rated as somewhat unacceptable (i.e., two are below the 0 midline, and two just above it) even when the civilian actions are also lethal. By contrast, in the right panel, for participants with very high legitimacy beliefs, lethal officer actions are acceptable, well above the midline, when civilian actions are also lethal. This 
suggests that there may be a willingness among people with high legitimacy beliefs to accept lethal officer force as a viable response to lethal civilian force, but people with low legitimacy beliefs may rarely view lethal force as acceptable, even when they are confronting very severe civilian actions.
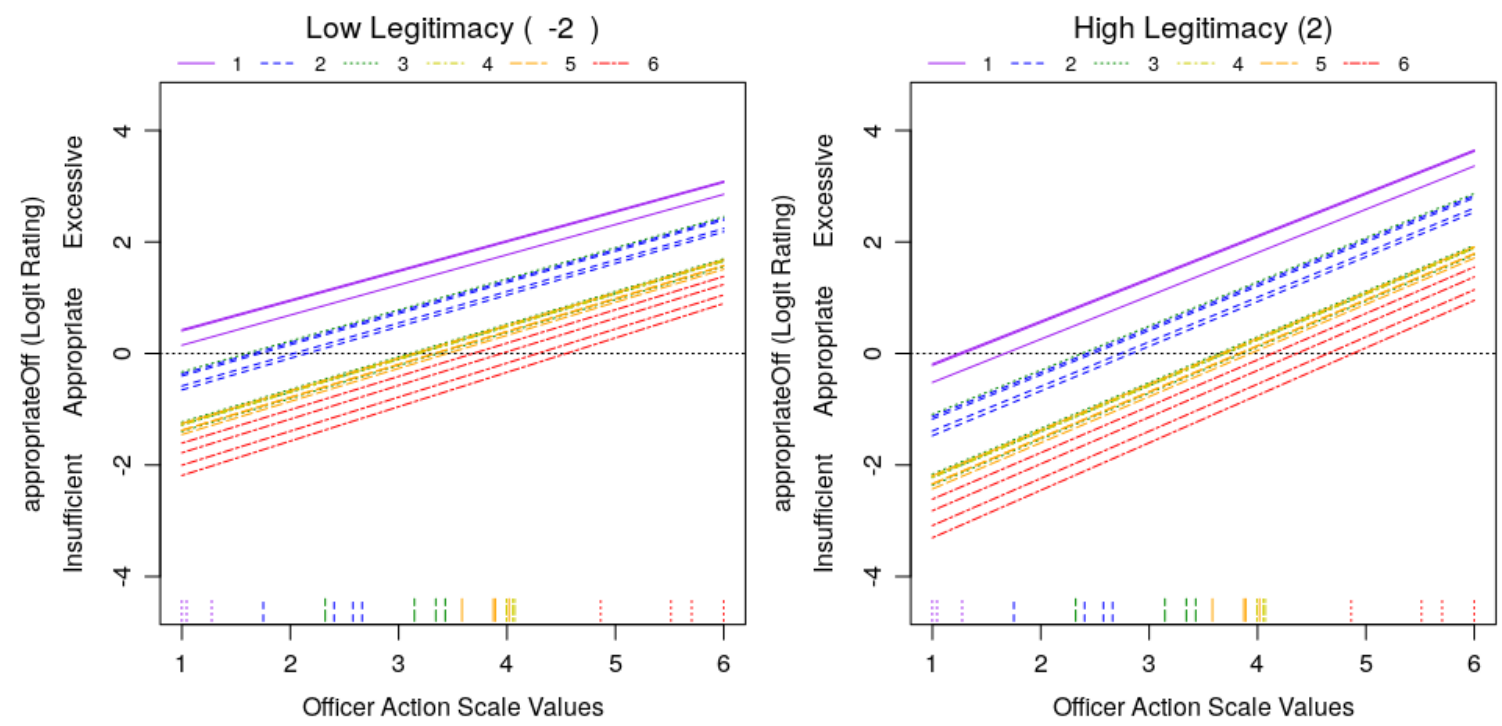

Figure 5. Regression model trend lines for officer appropriateness ratings. appropriateOff $=$ appropriateness rating of officer action. See Figure 3 for a detailed description of the figure components.

Officer appropriateness ratings. Recall that for appropriateness of an action, the response slider was labeled "appropriate" at its midpoint, "insufficient" at its low end, and "excessive" at its high end. Therefore an increase on this scale is not always an increase in appropriateness, because an increase on the high end of the scale is actually away from appropriate and toward excessive. Figure 5 has a horizontal dotted line marking the midpoint of the scale, that is, ratings at the point labeled "appropriate." Trend lines for appropriatenss of officer action are plotted in Figure 5. The lines increase as officer action severity increases, meaning that ratings transition from insufficient through appropriate to excessive as officer actions become more severe. The regression coefficient $\beta_{2}$ had a posterior mode of 0.69 (with 95\% HDI from 0.66 to 0.73 ).

The regression coefficient on civilian-action severity, $\beta_{1}$, had a posterior mode of -0.53 (with $95 \%$ HDI from -0.56 to -0.50 ), indicating that ratings of officer appropriateness transitioned from excessive to appropriate to insufficient as civilian-action severity increased. The negative regression coefficient is reflected in Figure 5 by the decreasing intercepts of the the civilian-action lines as they become more severe.

Intriguingly, visual inspection of Figure 5 indicates that lethal officer actions tended to be rated on the excessive side of "appropriate." That is, in both panels of Figure 5 the trend lines for the most severe officer actions (scale values of 5.0 to 6.0 on the horizontal axis) fall above the 0 
midline, even when the civilian actions are also lethal (i.e., red dot-dash lines). Thus, even when the civilian used lethal force, a lethal response by the officer is rated toward excessive rather than squarely appropriate.

To further investigate this trend, we isolated the subset of trials in which the officer and civilian actions exactly matched (or corresponded in the case of differing officer/civilian actions). For example, matched trials for "handgunChest" would include only trials in which the civilian and the officer both shot each other in the chest. We then modeled ratings of officer appropriateness for each action while including legitimacy beliefs as a covariate:

$$
\hat{y}_{a}=\alpha_{0, a}+\alpha_{1} \cdot \ell
$$

where $\hat{y}_{a}$ is the predicted rating (logit transformed and censored) and where $a(1-22)$ indexes the action. This analysis yielded intercept coefficients $\left(\alpha_{0, a}\right.$ in Eqn. 3$)$ that reflect the estimated appropriateness rating for each action when legitimacy beliefs are at their mean (recall that legitimacy beliefs are standardized, so 0 is the mean). Notice that this analysis does not involve estimating latent action severities. See supplementary material for detailed analysis code and further details (https://osf.io/aqfeh).

Importantly, the appropriateness question was unique among our dependent measures in that it provided participants with a middle anchor labeled "appropriate" in addition to the two end point anchors of "insufficient" and "excessive." As a result, analyzing departures from the midpoint is meaningful for this question, and matched actions would be expected to fall exactly at the midpoint if participants general expectations are that officers should be meeting civilian resistance with the same level of force.

As seen in Figure 6, appropriateness ratings for low-force matched actions fall very close to the midpoint of the scale. However, as actions become more severe (toward the right side of Figure 6), the predicted rating rises toward the excessive side of the scale. That is, even when the officer responds with the same action as the civilian, physically forceful officer actions still tend to be rated as somewhat excessive. In particular, the officer reactions rated as especially excessive include headButt, punchFace, headSlam, and vehicle, even in response to the identical action by the civilian. These actions are not intuitively normative for police officers, and therefore may be judged to be particularly excessive. On the other hand, it is normative for police officers to use their officially-issued hand gun, which may explain why handgunChest and handgunHead have mean ratings near the "appropriate" midline. An unexpected result in Figure 6 is that handcuff is rated as excessive, despite it being a normative police action. We believe this result is idiosyncratic for the particular matched civilian action, pulling away. Whereas pulling away has physical force comparable to handcuffing, pulling away by itself may seem not to merit handcuffing. Celestin and Kruschke (2019) provided more extensive discussion of the normativity of actions in terms of the estimated scale values of the actions.

Overall, this matched-action analysis is largely congruent with the primary analysis and sug- 


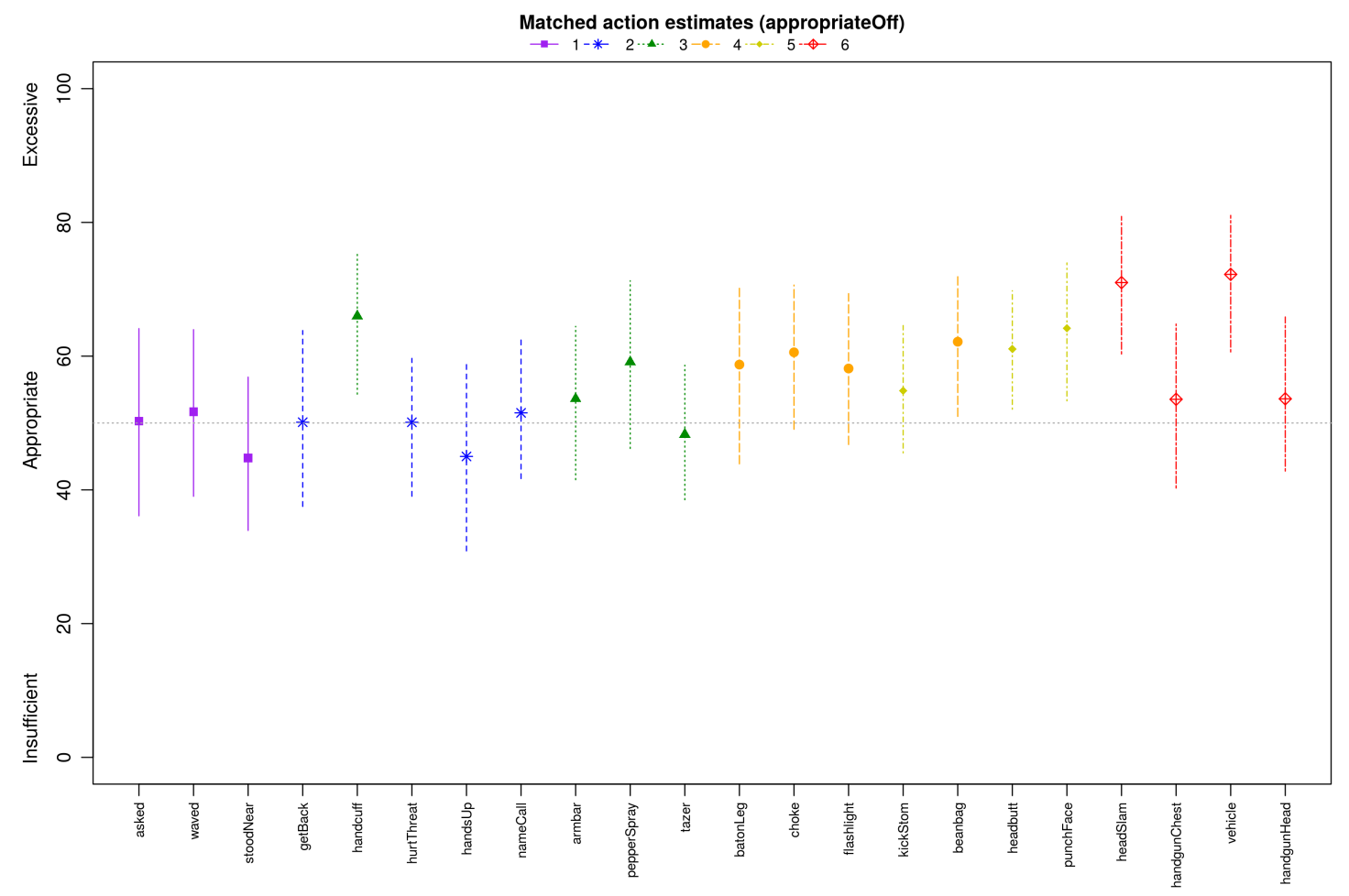

Figure 6. Mean ratings of officer appropriateness using only matched civilian/officer actions ( $\alpha_{0, a}$ in Eqn. 3). Vertical segments show 95\% HDI's. Vertical axis shows ratings on original scale, whereas analysis was performed on logit-transformed (and censored) ratings. Actions on the horizontal axis are ordered according to their latent severity (Celestin \& Kruschke, 2019). Symbols and colors indicate SOLOF level (as in Figure 1).

gests that lay evaluators may judge an officer reaction that matches a civilian action to be somewhat excessive. However, there are some inconsistencies between analyses. In Figure 5, all four lethalaction lines seem to fall above the midpoint at their matched action rug-plot points, and to roughly the same extent. This contrasts with the result in Figure 6 where the two gun-related actions fall closer to the midpoint. A second discrepancy is visible in the regression lines of Figure 5 which suggest that the ratings for handcuffing (in response to the matched civilian action "pullingAway") should be roughly at the midpoint or slightly below (depending on $\ell$ ); this stands in contrast to Figure 6 which indicates that handcuffing falls above the midline. These discrepancies result from the flexibility of Equation 3 relative to the more restrictive linearity of Equation 2. On the other hand, the analysis of matched actions involved only a small subset of data, while the full regression analysis involved all the data. The general trend of physically forceful officer actions being rated on the excessive side of appropriate remains supported by both analyses.

Returning now to the primary analysis in Figure 5, the effect of legitimacy beliefs can be discerned from visual comparison of the two panels in Figure 5. At the right edges of the two pan- 
els, the trend lines rise to approximately the same heights of excessiveness. But at the left edges of the two panels, the trend lines are lower, toward "insufficient," for the high-legitimacy panel. That is, participants with very high legitimacy beliefs tended to rate mild officer actions as more insufficient than participants with very low legitimacy beliefs. This difference between panels is expressed mathematically by the combined effects of the regression coefficients involving legitimacy. The coefficient $\beta_{3}$ had a posterior mode of -0.07 (with $95 \%$ HDI from -0.11 to -0.03 ) indicating that higher legitimacy participants tended to have lower ratings overall (i.e., more insufficient, less excessive), but the coefficient $\beta_{5}$ had a posterior mode of 0.06 (with 95\% HDI from 0.03 to 0.09 ) indicating that higher legitimacy participants tended to have steeper slopes on officer severity. The combined effect of the coefficients is that high-legitimacy participants tend to rate mild officer actions as more insufficient than low-legitimacy participants (left edge of the panels), but high-legitimacy participants tend to rate severe officer actions about the same as low-legitimacy participants (right edge of the panels). The interaction of civilian and officer action severity represented by the $\beta_{6}$ coefficient was close to zero with an HDI that included zero, indicating that appropriateness ratings changed at a consistent rate across actions.
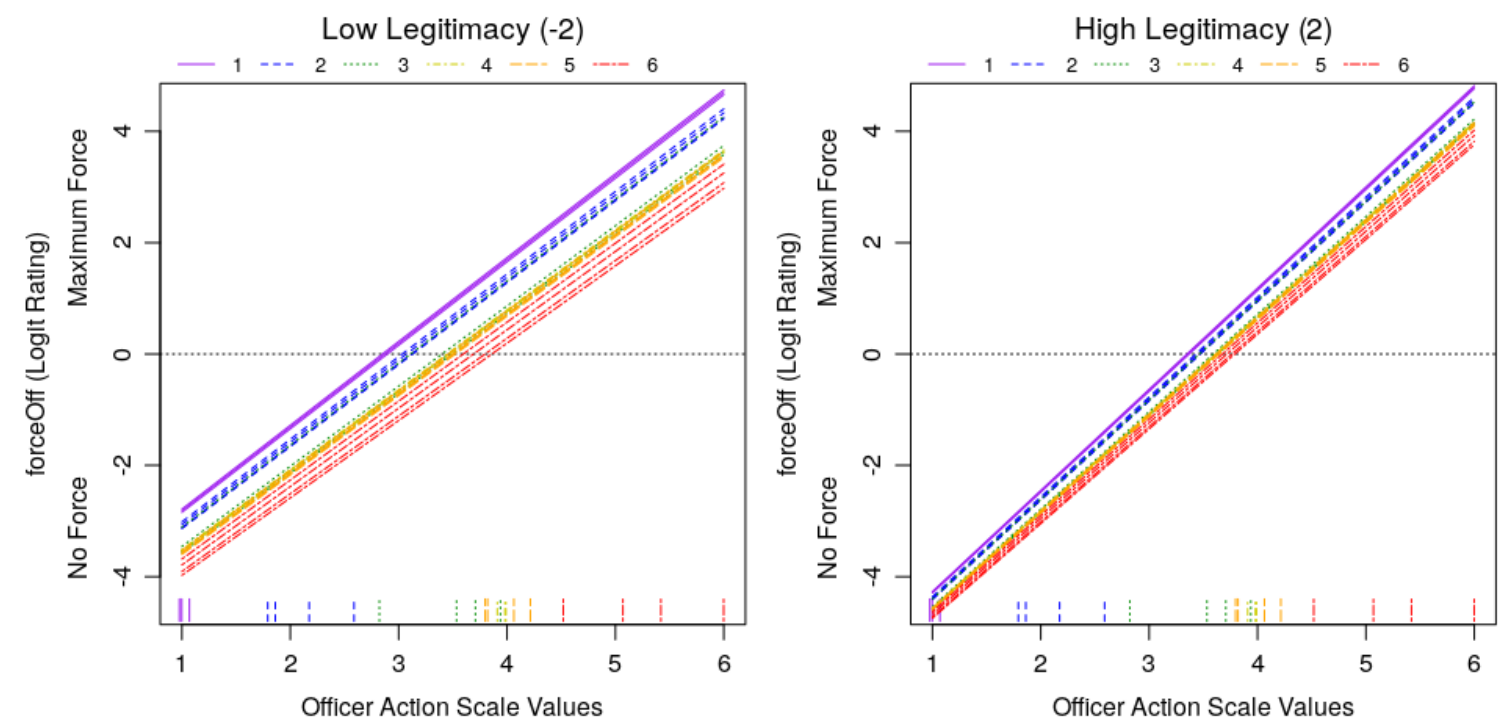

Figure 7. Regression model trend lines for officer force ratings. forceOff $=$ force rating of officer action. See Figure 3 for a detailed description of the figure components.

Officer force ratings. The trend lines for ratings of the forcefulness of an officer reaction are plotted in Figure 7. Perhaps the most prominent feature of the graphs, in contrast to previous graphs, is that the lines for different civilian actions are close together, especially for participants with high legitimacy (right panel). This dense packing of the lines makes intuitive sense: The physical forcefulness of an action is inherent in the action itself, regardless of what may have happened before the action. The small separation of the lines is determined mathematically by the value of 
regression coefficient $\beta_{1}$, which had a posterior mode of only -0.22 (95\% HDI from -0.25 to $-0.20)$. The negative sign indicates that people rated the physical forcefulness of an officer reaction less severely as the civilian-action severity increased. But the rate of decline was small compared to moral ratings (cf. for punishment $\beta_{1}=-1.13$ ). The slope on civilian-action severity was modulated slightly by legitimacy beliefs, as can be seen in the tighter packing of the lines for high legitimacy (right panel) than for low legitimacy (left panel). This interaction with legitimacy is governed mathematically by regression coefficient $\beta_{4}$, which had a posterior mode of 0.04 (and 95\% HDI from 0.01 to 0.06$)$.

Legitimacy also had small modulating effects on the baseline and slope with respect to officeraction severity. The baseline decreased slightly as legitimacy beliefs increased, with $\beta_{3}$ having a posterior mode of -0.09 (and 95\% HDI from -0.13 to -0.05 ). Simultaneously, the slope on officer-action severity increased slightly as legitimacy belief increased, with $\beta_{5}$ having a posterior mode of 0.08 (and $95 \%$ HDI from 0.05 to 0.11 ). Together, these influences of legitimacy are most noticeable at the left edges of the panels in Figure 7: participants with low legitmacy beliefs tended to rate mild officer actions as having a bit more forcefulness than the ratings from participants with high legitimacy beliefs.

Summary of officer action ratings. Punishment ratings increased as officer-action severity increased, and punishment ratings decreased as civilian-action severity increased. Consistent with those trends, acceptability ratings lessened as officer actions became more severe, while acceptability ratings escalated as civilian actions became more severe. Punishment and acceptability ratings were modulated by the interaction of civilian and officer actions such that they increased/decreased at greater rates when civilian actions were less severe. Therefore, participants were judging the moral aspects of officer actions in the context of the preceding civilian action.

As participant legitimacy beliefs increased, overall punishment ratings decreased and acceptability ratings increased. Notably, participants with very low legitimacy beliefs viewed lethal officer actions as unacceptable even when the civilian actions were also lethal. This finding suggests it is possible that lethal force is not viewed as a viable police response for people with very low legitimacy beliefs about police.

With respect to ratings of appropriateness, lethal force by an officer was viewed as slightly excessive even after lethal civilian force and regardless of participants' legitimacy beliefs. On the other hand, participants with high legitimacy beliefs tended to rate mild officer reactions as insufficient more than participants with low legitimacy beliefs.

Finally, perceived physical force of officer actions increased with action severity, but decreased slightly as civilian actions became more severe. In principle, a judgment of an action's physical forcefulness should depend only on the action itself and not on any preceding action. The participants in these studies showed an influence of the preceding action, with low-legitimacy participants showing a slightly larger influence, but the influence was much smaller than in the ratings of moral consequences. 

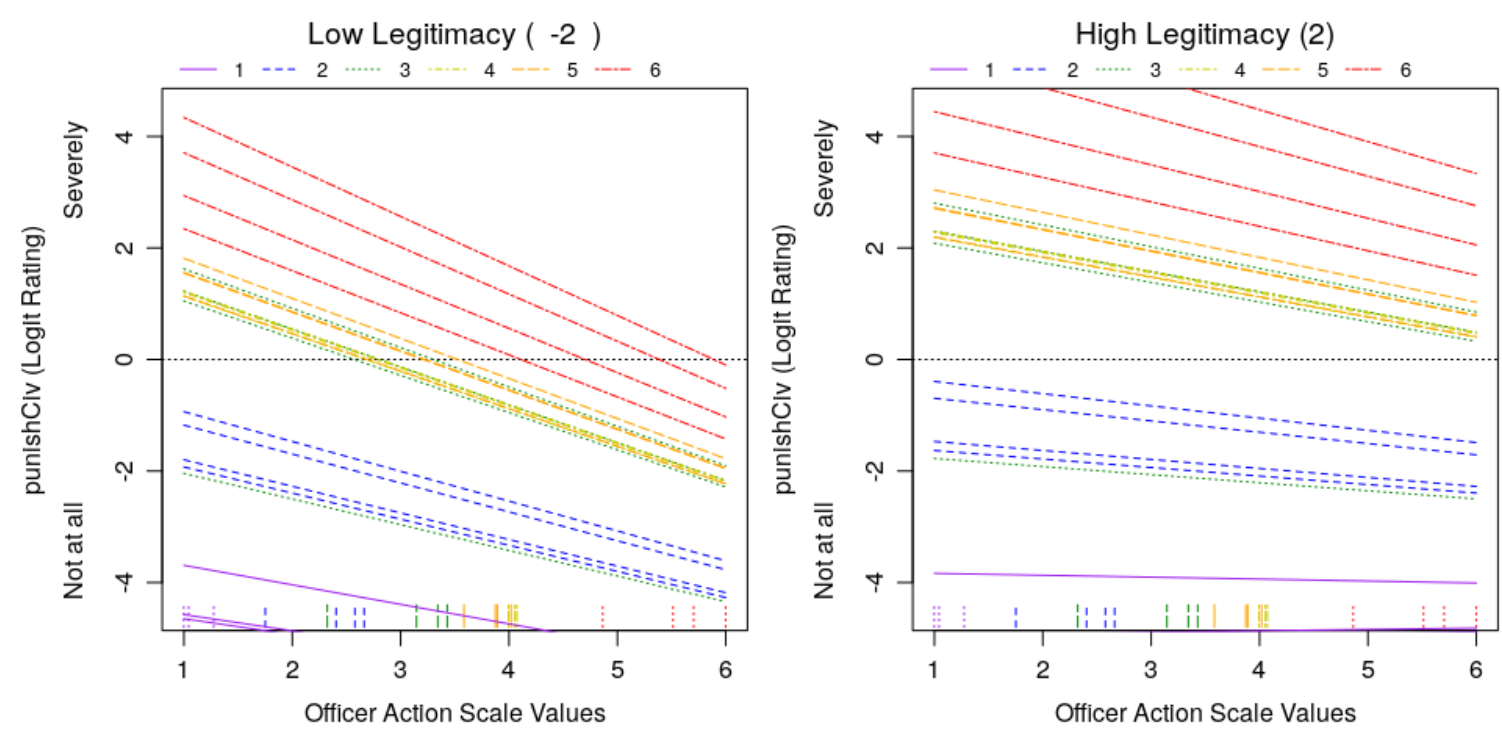

Figure 8. Regression model trend lines for civilian punishment ratings. punishCiv = punishability rating of civilian action. Notice the horizontal axis is officer action severity. See Figure 3 for a detailed description of the figure components.

Civilian punishment ratings. Trend lines for punishment ratings of civilian actions (after a preceding officer action) are plotted in Figure 8. Notice that the horizontal axis continues to represent officer action severity, as in previous graphs. And, as before, the effect of civilian action severity is represented by the spread between the lines for different civilian actions. In can be seen in both panels of Figure 8 that the lines are quite spread out, indicating a large influence of civilianaction severity on the punishability of the action. Regression coefficient $\beta_{1}$ had a posterior mode of 1.72 (95\% HDI from 1.67 to 1.78). Moreover, the spread of the lines is larger as legitimacy beliefs increase; coefficient $\beta_{4}$ had a posterior mode of 0.11 (95\% HDI from 0.07 to 0.16 ).

In both panels of Figure 8 the lines descend, indicating that the punishability of a civilian action declines as the severity of the preceding officer action increases. This decline is captured by coefficient $\beta_{2}$ which had a posterior mode of -0.43 (and 95\% HDI from -0.46 to -0.39 ). Interestingly, the magnitude of the decline depended on the legitimacy belief of the participant, with low-legitimacy beliefs (left panel of Figure 8) endorsing a steeper decline in punishability than high-legitimacy beliefs (right panel of Figure 8). This change in slopes is captured by coefficient $\beta_{5}$ which had a posterior mode of 0.08 (95\% HDI from 0.04 to 0.11 ).

The interaction between civilian and officer action severity controlled by regression coefficient $\beta_{6}$ had a negative posterior mode of -0.12 (and 95\% HDI from -0.15 to -0.09 ). This indicates that as officer action severity increases, punishment judgments of civilian actions increase less steeply when officer actions are more severe. This interaction is visible in both panels of Figure 8 by noticing that the slope of low-severity civilian actions (i.e., the purple solid lines) is much 
less steep than the slope of high-severity civilian actions (i.e., the red dot-dash lines).

Visual inspection of the two panels of Figure 8 also suggests that punishment ratings tended to be higher overall for participants with high legitimacy beliefs. This is robustly verified by the regression coefficient $\beta_{3}$ which had a posterior mode of 0.38 (and 95\% HDI from 0.33 to 0.44 ).

It is interesting that the influence of legitimacy on baseline punishability is almost as strong (in magnitude) for ratings of civilian actions as for officer actions (i.e., $\beta_{3}=0.38$ for civilian actions and $\beta_{3}=-0.51$ for officer actions). Moreover, the influence of legitimacy on the effect of civilian action severity is stronger for ratings of civilian punishability than ratings of officer punishability (i.e., $\beta_{4}=0.11$ for civilian actions and $\beta_{4}=-0.01$ for officer actions), and the influence of legitimacy on the effect of officer action severity is stronger for ratings of civilian punishability than ratings of officer punishability (i.e., $\beta_{5}=0.08$ for civilian actions and $\beta_{5}=-0.03$ for officer actions). The differences in magnitudes of the $\beta_{4}$ and $\beta_{5}$ coefficients across civilian and officer ratings are marginal, but similar trends appear in judgments of acceptability and appropriateness. In other words, the influence of legitimacy is at least as strong for judgments of civilian reactions to police as for judgments of police reactions to civilians.
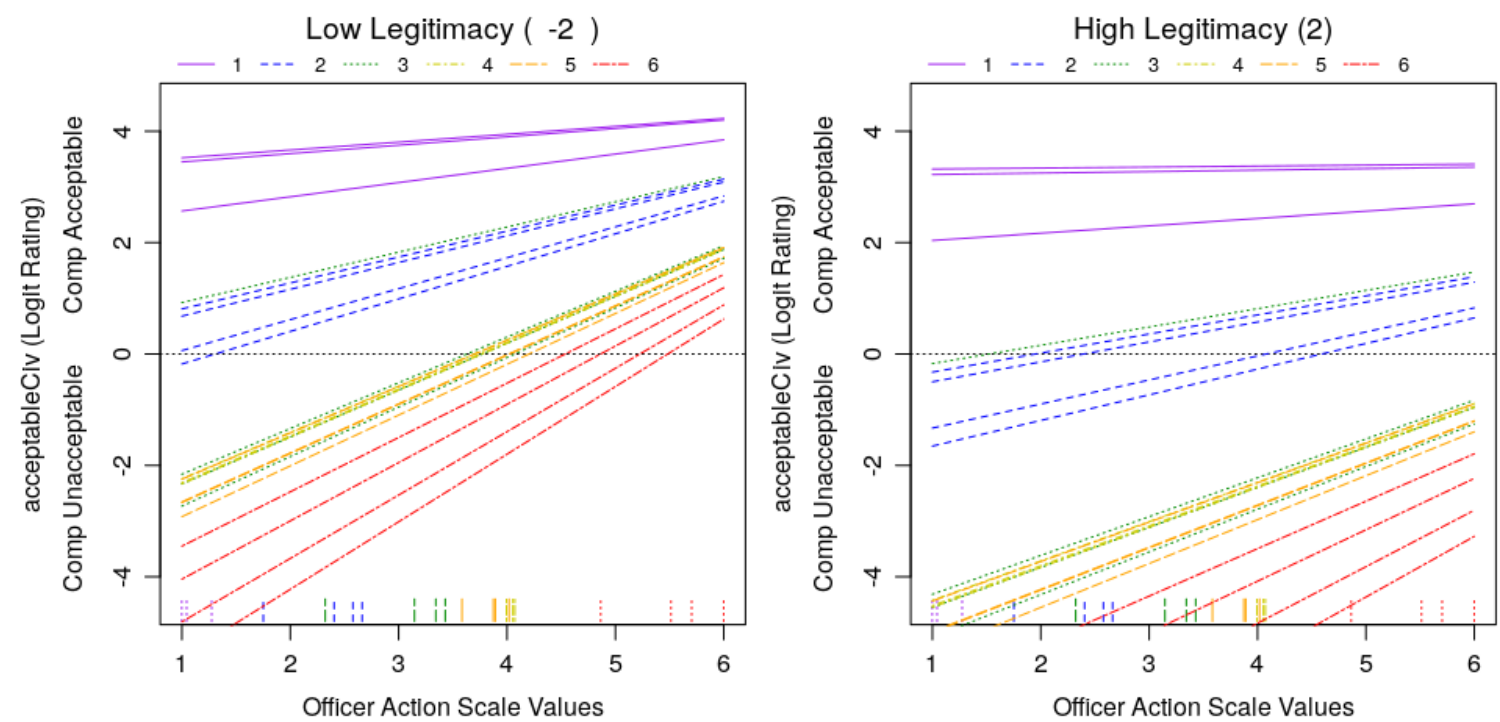

Figure 9. Regression model trend lines for civilian acceptability ratings. acceptableCiv = acceptability rating of civilian action. Notice the horizontal axis is officer action severity. See Figure 3 for a detailed description of the figure components.

Civilian acceptability ratings. Acceptability ratings of civilian actions were consistent with punishment ratings: the patterns were inverses of each other. Trend lines for acceptability ratings of civilian actions (i.e., reactions to officer actions) are shown in Figure 9. Again the lines are quite spread out, indicating a large influence of civilian-action severity on the acceptability of the action. Regression coefficient $\beta_{1}$ had a posterior mode of -1.56 (95\% HDI from -1.63 to 
-1.51). Moreover, the spread of the lines is larger (more negative) as legitimacy beliefs increase; coefficient $\beta_{4}$ had a posterior mode of -0.15 (95\% HDI from -0.20 to -0.11 ).

In both panels of Figure 9 the lines ascend, indicating that the acceptability of a civilian action increases as the severity of the preceding officer action increases. This increase is captured by coefficient $\beta_{2}$ which had a posterior mode of 0.62 (95\% HDI from 0.57 to 0.66 ). There is marginal evidence that the magnitude of the increase depended on the legitimacy belief of the participant, with low-legitimacy beliefs (left panel of Figure 9) endorsing a steeper increase in acceptability than high-legitimacy beliefs (right panel of Figure 9). This change in slope is captured by coefficient $\beta_{5}$ which had a posterior mode of -0.03 (95\% HDI from -0.07 to 0.01 ).

The interaction between civilian and officer action severity controlled by regression coefficient $\beta_{6}$ had a positive posterior mode of 0.21 (and 95\% HDI from 0.18 to 0.25 ). This indicates that as officer action severity increases, acceptibility judgments of low severity civilian actions increases only slightly (if at all), while acceptability of more severe civilian actions increases much more. This interaction is visible in both panels of Figure 8 by noticing that the slope of low-severity civilian actions (i.e., the purple solid lines) is much less steep than the slope of high-severity civilian actions (i.e., the red dot-dash lines).

Visual inspection of the two panels of Figure 9 also suggests that ratings of acceptability of civilian actions tended to be lower overall for participants with high police-legitimacy beliefs. This is robustly verified by the regression coefficient $\beta_{3}$ which had a posterior mode of -0.53 (95\% HDI from -0.59 to -0.46$)$.

The influence of legitimacy on baseline acceptability is as strong (in magnitude) for civilian actions as for officer actions (i.e., $\beta_{3}=-0.50$ for civilian actions and $\beta_{3}=0.51$ for officer actions). Moreover, the influence of legitimacy on the effect of civilian action severity is stronger for ratings of civilian acceptability than ratings of officer acceptability (i.e., $\beta_{4}=-0.15$ for civilian actions and $\beta_{4}=0.04$ for officer actions), and the influence of legitimacy on the effect of officer action severity is no weaker for ratings of civilian acceptability than ratings of officer acceptability (i.e., $\beta_{5}=-0.03$ for civilian actions and $\beta_{5}=0.05$ for officer actions, HDIs both include 0 ). In other words, the influence of legitimacy is at least as strong for judgments of civilian reactions to police as for judgments of police reactions to civilians.

Interestingly, the severe civilian action lines in the low legitimacy panel $(\ell-2)$ appear well above the midpoint of acceptability when officer action severity is high, while they remain well below the midpoint even at extreme officer severity levels in the high legitimacy panel $(\ell+2)$. That is, the right panel of Figure 9 shows that for participants with the highest legitimacy beliefs, violent civilian actions are not acceptable even when in response to lethal officer actions. In contrast, participants with the lowest legitimacy beliefs rate lethal civilian actions well above the acceptability midpoint when officer actions are lethal.

Civilian appropriateness ratings. The trend lines for appropriateness of civilian action are plotted in Figure 10. Recall that the anchors for the response scale went from "insufficient" through "appropriate" to "excessive." The regression coefficient on civilian action, $\beta_{1}$, had a pos- 

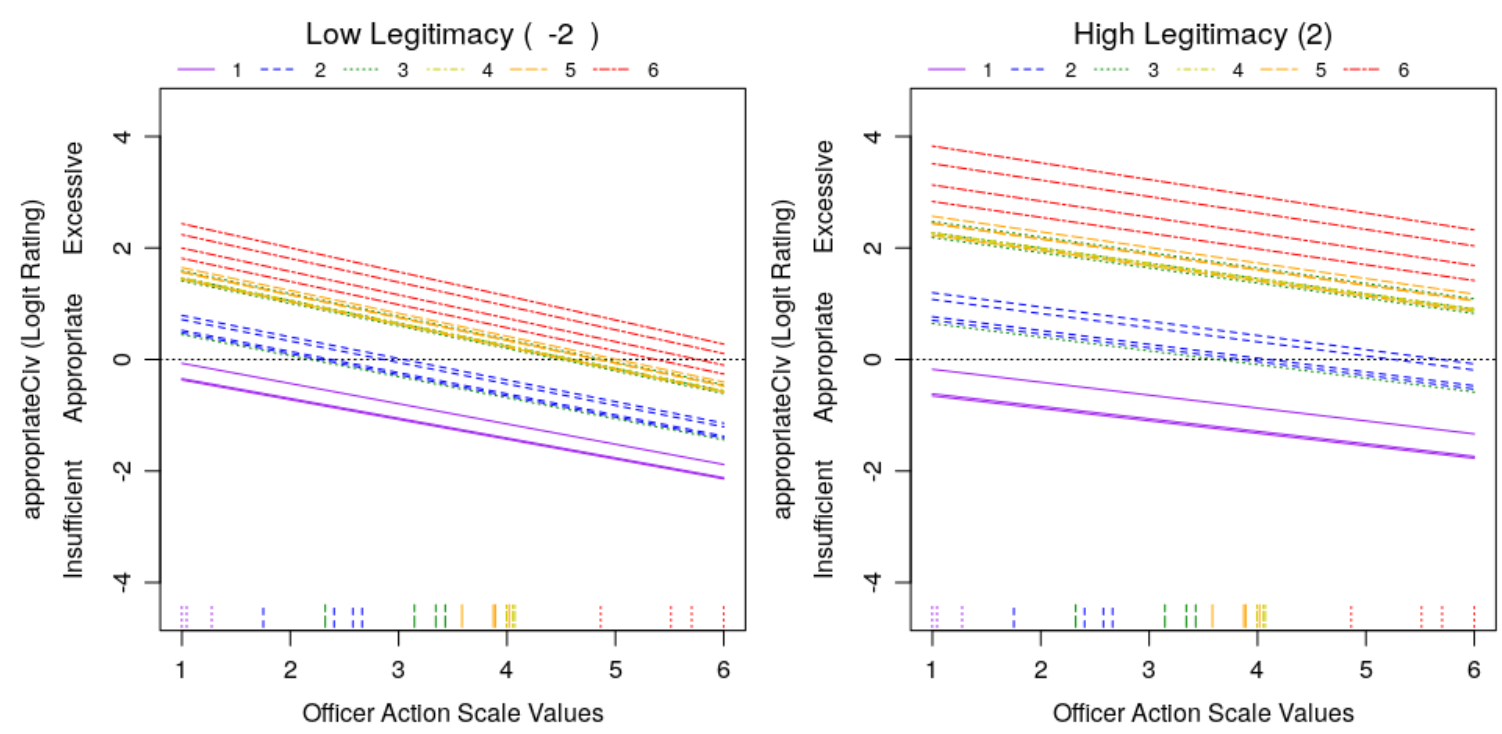

Figure 10. Regression model trend lines for civilian appropriateness ratings. appropriate$\mathrm{Civ}=$ appropriateness rating of civilian action. Notice the horizontal axis is officer action severity. See Figure 3 for a detailed description of the figure components.

terior mode of 0.69 (with 95\% HDI from 0.66 to 0.73 ), indicating that judgments of civilian action transitioned from insufficient to appropriate to excessive as their severity increased. This slope on civilian action depended on legitimacy belief, as coefficient $\beta_{4}$ had a posterior mode of 0.08 (with 95\% HDI from 0.05 to 0.12 ). This effect can be seen by comparing the two panels of Figure 10, in which the lines are more spread out for $\ell=+2$ than for $\ell=-2$.

Ratings declined with the severity of the preceding officer action, as shown by the descending lines in Figure 10. Coefficient $\beta_{2}$ had a posterior mode of -0.33 (with $95 \%$ HDI from -0.36 to -0.30 ). The slope of the lines did not depend much on legitimacy ( $\beta_{5}$ had a posterior mode of 0.03 with $95 \%$ HDI from 0.00 to 0.07 ), as can be seen by the only subtle change in slope across panels.

Perhaps the most prominent feature of Figure 10 is that severe civilian actions (dash-dot red lines) tend to be rated toward excessive (above the midline) for very-high legitimacy respondents, even when the preceding officer action is also severe. But severe civilian actions (dash-dot red lines) tend to be rated as appropriate (near the midline) for very-low legitimacy respondents when the preceding officer action is also severe. This difference is captured in part by the overall influence of legitimacy on the intercept, given by coefficient $\beta_{3}$, which had a posterior mode of 0.22 (with 95\% HDI from 0.17 to 0.27 ). The effect of legitimacy on baseline appropriateness is stronger for judgments of civilian actions than for judgments of officer actions $\left(\beta_{3}=0.22\right.$ for civilian actions and $\beta_{3}=-0.07$ for officer actions).

We also analyzed responses to matched civilian reactions, just as we did for officer reactions in Equation 3. Figure 11 plots the intercept estimates of the model, which indicate the predicted 


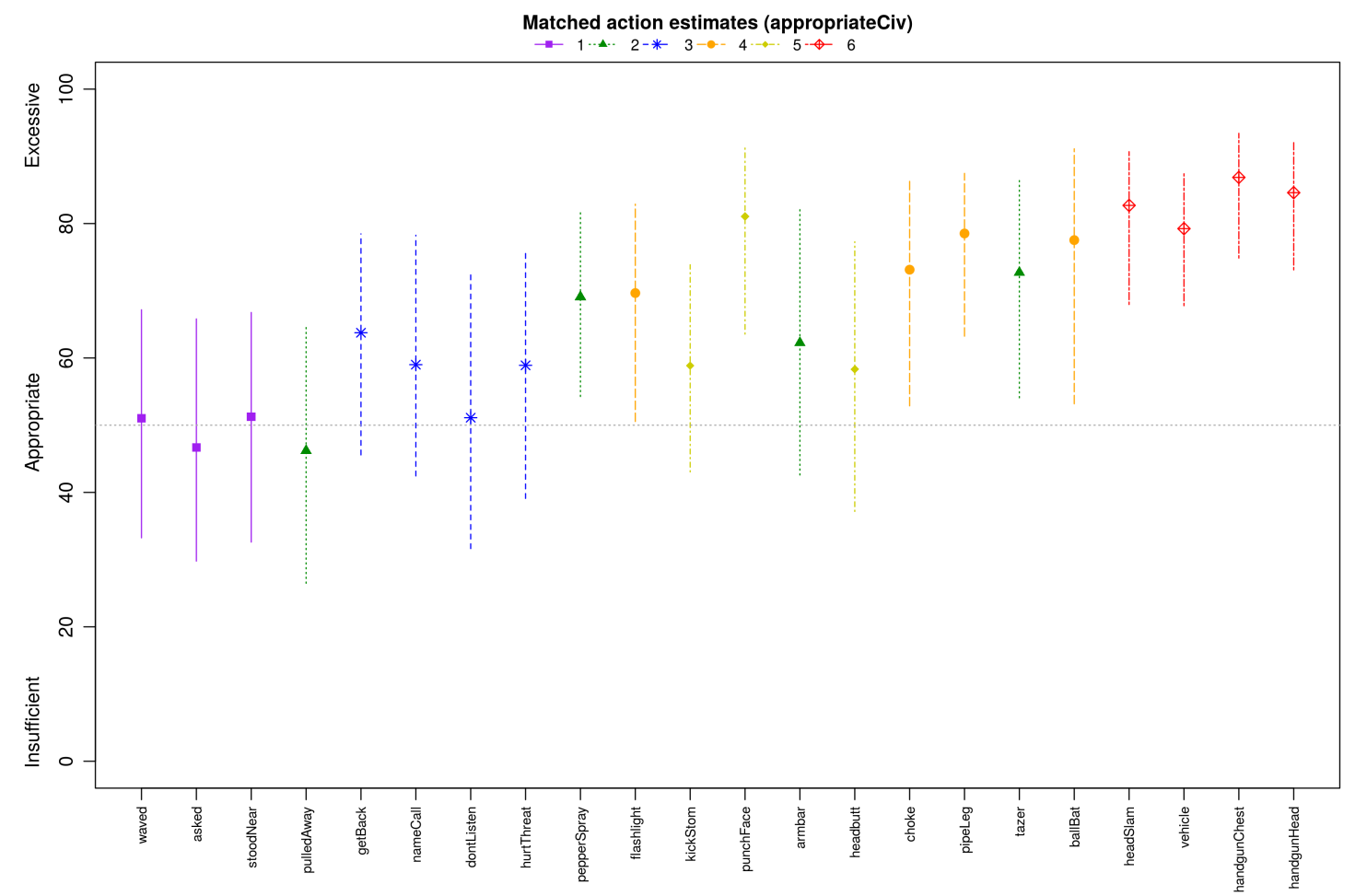

Figure 11. Mean ratings of civilian appropriateness using only matched civilian/officer actions. Vertical segments show 95\% HDI's. Vertical axis shows ratings on original scale, whereas analysis was performed on logit-transformed (and censored) ratings. Actions on the horizontal axis are ordered according to their latent severity (Celestin \& Kruschke, 2019). Symbols and colors indicate SOLOF level (as in Figure 1).

appropriateness rating at mean legitimacy $(\ell=0)$ for each civilian action. It is clear in Figure 11 that the majority of civilian actions fall above the appropriateness midpoint toward the excessive end of the scale, with the more severe civilian actions being closer to the excessive end of the scale.

A visual comparison of Figures 6 and 11 shows that the rated excessiveness of officer matched reactions tends not to be as extreme as civilian matched reactions. We suspect this difference arises from different expectations of police and civilian behavior. Police are legally authorized to use force but civilians are rarely authorized to use force against police. That is, any violent civilian action is excessive by default unless accompanied by some additional justification.

Civilian force ratings. Trend lines for ratings of forcefulness of civilian action are shown in Figure 12. As indicated by large spread between lines, there was a strong influence of civilian action severity, with $\beta_{1}$ having a posterior mode of 1.58 (and 95\% HDI from 1.52 to 1.64). The spread grew somewhat with legitimacy, as $\beta_{4}$ had a posterior mode of 0.12 (with $95 \%$ HDI from 0.09 to 0.15$)$.

The overall ratings of civilian force increased slightly with legitimacy, as $\beta_{3}$ had a posterior 

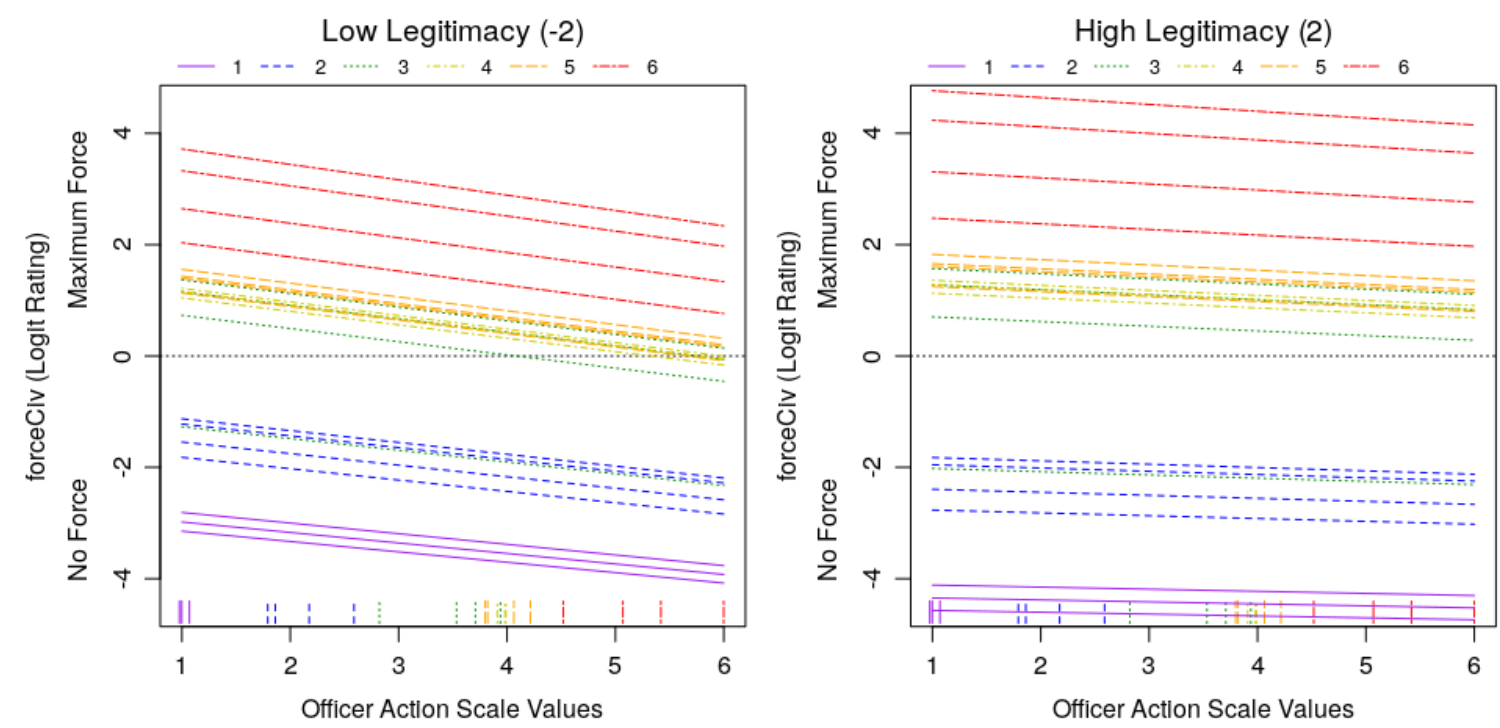

Figure 12. Regression model trend lines for civilian force ratings. forceCiv $=$ force rating of civilian action. Notice the horizontal axis is officer action severity. See Figure 3 for a detailed description of the figure components.

mode of 0.05 (with 95\% HDI from 0.01 to 0.09 ). This can be discerned visually in Figure 12 by the subtle overall increase in the height of lines in the right panel relative to the left panel.

Perhaps the most interesting aspect of the civilian force ratings is that they depend (to a small degree) on the preceding officer action. The trend lines in Figure 12 descend; coefficient $\beta_{2}$ had a posterior mode of -0.15 (with $95 \%$ HDI from -0.18 to -0.13 ). Notice that the magnitude of the influence of preceding action on this physical attribute is far smaller than for moral attributes. Interestingly, the influence of the preceding officer action is less for high-legitimacy participants than for low-legitimacy participants ( $\beta_{5}$ had a posterior mode of 0.04 with $95 \%$ HDI from 0.01 to 0.07), as can be seen in Figure 12 by the less steep lines in the right panel.

Summary of civilian action ratings. Ratings of civilian punishment decreased as the severity of preceding officer action increased, but this decrease was stronger for participants with low legitimacy beliefs.

Acceptability of civilian action increased as the severity of preceding officer action increased, and this increase was stronger for participants with low legitimacy beliefs. Participants with very high legitimacy beliefs tended to rate severe civilian actions as unacceptable even when preceded by a severe officer action, unlike participants with low legitimacy beliefs. Civilian punishment and acceptability ratings were modulated by the interaction of civilian and officer actions such that they decreased and increased, respectively, at greater rates when civilian actions were more severe. That is, low-severity civilian actions are always highly acceptable and not deserving of punishment, but high-severity civilian actions become much more acceptable and much less deserving of punishment as officer actions become severe-especially for participants with low legitimacy beliefs. 
Appropriateness of civilian action went from insufficient to excessive as action severity increased, but had the reverse trend as officer action severity increased. Participants with very high legitimacy beliefs tended to rate severe civilian actions as excessive even when preceded by a severe officer action, unlike participants with low legitimacy beliefs.

In general, the influence of legitimacy beliefs was just as strong on ratings of civilian reactions to police as on ratings of officer reactions to civilians. This is interesting because the questions for assaying legitimacy are explicitly focused on attitudes about police, not about civilians. Believing that police authority is not very legitimate need not, in priciple, be related to beliefs about the justifiability of civilian violence. In fact, it is reasonable to imagine that violence might be viewed as generally immoral regardless of the aggressor, and that individuals who exhibit low legitimacy beliefs about police are also generally violence averse. Thus, it striking that the moral acceptability of civilian violence appears to be so strongly anti-correlated with beliefs about police legitimacy in the patterns we observe in these data.

Finally, perceived physical force of civilian actions depended to a small degree on the severity of the preceding officer action, and this influence of officer action was stronger for low-legitimacy participants.

\section{Discussion and Conclusions}

We measured lay evaluations of police and civilian use of force using a unique paradigm incorporating actions from the complete range of law enforcement force options. The results provide

a detailed view of the way lay observers make moral and physical evaluations of representative police and civilian actions, and the effects of legitimacy beliefs on those evaluations.

Our results showed that as officer actions become more severe, they are viewed as more physically forceful, and officer punishment and excessiveness ratings increase while acceptability ratings decrease. As civilian actions become more severe, they are also viewed as more physically forceful, and civilian punishment and excessiveness ratings increase while civilian acceptability ratings decrease. Moreover, both evaluations depend on the severity of the preceding action, such that the severity of the preceding action increases acceptability and decreases punishability of subsequent severe actions. Evaluations of physical force also depend, to a lesser magnitude, on the severity of the preceding action. These results demonstrate rough congruence between lay evaluations of police and civilian use of force and law enforcement categorization strategies that organize force according to its severity. Consequently, they reveal a point of general agreement between citizens and police who both evaluate the moral justifiability of police use of force in relation to the magnitude of civilian violence with which they are confronted. More surprisingly, for lay judgments this relationship holds for civilian violence relative to police actions, and the magnitude of the effect is just as large.

Beyond these primary effects, individual differences in legitimacy beliefs altered both moral and physical evaluations of officer and civilian violence. As legitimacy beliefs decreased, officer 
punishment ratings were higher and acceptability ratings were lower. Thus, as one might expect, low legitimacy individuals are generally skeptical of the moral legitimacy of police use of force across the entire spectrum of actions (i.e., not only for extreme police actions). Intriguingly, highlegitimacy individuals also exhibit increased perceptions of moral legitimacy for civilian violence, even for lethal actions, although the rate of increase is attenuated relative to low-legitimacy individuals.

Legitimacy beliefs also affected judgments of physical force (though not as much as for moral judgments), with low-legitimacy participants showing a stronger influence of preceding civilian action on judgments of officer force, and a stronger influence of preceding officer action on judgments of civilian force. This suggests that moral judgments can bleed over onto the evaluation of physical severity such that what "should happen" can influence perceptions about what "did happen," at least to some degree.

Additionally, the influence of legitimacy was just as strong for judgments of civilian reactions to police as for judgments of police reactions to civilians. This result sheds new light on the relationship between legitimacy beliefs and moral evaluations of civilian violence against the police. Specifically, it indicates that beliefs about the legitimacy of police do not only represent attitudes toward criminal justice authorities, they are also a powerful predictor of the moral justifiability of civilian violence. These results imply that authorities who are viewed as illegitimate are not merely worthy of avoidance and disregard, but may be "appropriate" targets of "righteous" violence-a conclusion that is concordant with research documenting the general motivations for violence (Fiske \& Rai, 2014) and liberty/oppression as an anti-authority moral foundation (Iyer et al., 2012).

One possible explanation for the tendency of legitimacy to increase the morality of either police or civilian violence is that legitimacy shifts the extent to which each participant in a policecivilian encounter is perceived as a moral agent deserving of judgment, or a moral patient deserving of sympathy. Gray and Wegner (2009) proposed that moral judgments possess a fundamental structure in which parties involved are pigeon holed into either a perpetrator (agent) or a victim (patient), a process known as "moral typecasting" (see also Gray, Schein, and Ward (2014) and Schein and Gray (2017)). Viewed in this light, perhaps the inverse effects of legitimacy on police and civilian evaluations of violence reflect the tendency of low-legitimacy individuals to ascribe patiency primarily to citizens, while high-legitimacy individuals ascribe patiency more to police. This proposed role of moral typecasting is speculative and requires additional research.

From this rich array of results, perhaps the most surprising finding is that ratings of lethal officer force are consistently on the "excessive" side of appropriate, even when the preceding civilian action is also lethal, and even for high-legitimacy participants. This result was demonstrated by the analysis involving simultaneous estimation of latent scale values (see Figure 5) and by the analysis involving ratings of matched-severity actions (see Figure 6). The trend lines of Figure 5 suggest that when a preceding civilian action is lethal (in SOLOF category 6), an officer response that is squarely "appropriate" should be less severe, as low as SOLOF category 5 for low-legitimacy participants. Qualifying this general observation that lethal officer force always tends to be perceived 
as excessive are the observed differences in acceptability and punishment of officer and civilian actions across different levels of participant legitimacy beliefs. Specifically, low-legitimacy participants view civilian violence as acceptable and much less worthy of punishment when officer actions become sufficiently severe, while high-legitimacy participants seem much less willing to legitimate civilian violence. Importantly, these results demonstrate the need to take both civilian and officer actions jointly into account when formulating models of lay evaluations of police use of force, because the actions of both have meaningful effects on judgments of punishment, acceptability, appropriateness, and even physical magnitude.

\section{Limitations and Future Work}

All research has limitations, and the work we present here is no exception. One constraint is that we utilize brief textual action descriptions. These descriptions are realistic in the sense that citizens often read incomplete accounts about incidents of police/civilian confrontations on news and social media sites, but the emotional charge that accompanies video from bystanders, patrol vehicles, and body-worn cameras is likely blunted. Although it is conceivable that video stimuli would substantively alter the patterns we observe, we think it is more likely that amping up the emotionality of our stimuli would merely increase the magnitude of our effects. Moreover, video stimuli bear the cost of reduced control (e.g., they introduce myriad contextual details that are not present in text-based stimuli), and so they increase measurement noise. Nevertheless, future iterations of this work would benefit from exploring more naturalistic stimuli.

The current data provide a measure of judgments about the moral and physical magnitude of actions, but they do not directly assess what participants believe to be the most appropriate police response to a given civilian action. Moral evaluations provide indirect insight into what participants believe is an optimal police response to civilian violence, but future research should query participants directly about what they believe is the most appropriate police response to civilian actions across the entire force severity spectrum.

Finally, our results provide insight into the comparison between lay civilian evaluations in comparison to force continua that are representative of official law enforcement policies, but it is possible that the perceptions of individual law enforcement officers meaningfully differ from those policies. Thus, the extent to which actual police perceptions are more or less congruent with lay perceptions is currently unknown. Moreover, the level of incongruence between official policies and individual police officers might differ according to specialized roles that officers occupy in a law enforcement organization. For example, members of tactical teams (e.g., SWAT) might have different intuitions about force severity than school resource officers, uniform patrol officers might have different intuitions than plain clothes investigators, etc. Given these additional questions, future research should investigate police perceptions using the paradigm we present currently, and the organization roles of individual police evaluators should be taken into account as an explanatory variable. 


\section{Conclusions}

One reasonable conclusion from the results we present is that law-enforcement policies that allow officers to use force that matches or exceeds the severity of civilian resistance may be perceived as excessive, even by lay observers with strong beliefs in the legitimacy of police. It seems that lay observers expect police to react to civilian force with somewhat less severity than the civilian force with which they are confronted. This finding directly conflicts with typical policies that license police officers to use somewhat greater force in order to quickly control the situation, mitigate collateral harm, and achieve compliance. Attaining resolution between police and civilian perspectives may require some combination of education and tuning of use-of-force policy. Specifically, educating the public about SOLOF structure and the need for "one-level-up" police heuristics may increase the extent to which they are sufficiently knowledgeable about the details of police policy and also convinced of the moral justifiability of the current use-of-force models. Simultaneously, regular reevaluation of SOLOF-style categorization and accompanying heuristics by police policy-makers in order to emphasize police reactions that maximize alignment with public expectations according to the data we provide may prove useful. In the limit, attenuating the fundamental conflict we observe between lay perceptions and police policy is likely to be a complicated pursuit. Nevertheless, democratic principles demand that police decisions about appropriate levels of force have broad public support, and merging these two strategies (i.e., educating the public and re-evaluation of current use-of-force policy) with the current results in mind may be a good empirically-informed starting point to narrow the gap between police and civilian perceptions of what constitutes legitimate police violence. 
References

Alpert, G. P., \& Dunham, R. G. (2004). Understanding Police Use of Force: Officers, Suspects, and Reciprocity. Cambridge University Press. doi: 10.1017/ CBO9780511499449

Bell v. Wolfish, 441 U.S. 520. (1979).

Blinder, A., \& Mazzei, P. (2018, feb). As Gunman Rampaged Through Florida School, Armed Deputy 'Never Went In'. New York. Retrieved from https://www.nytimes.com/2018/02/22/us/nikolas-cruz -florida-shooting.html

Braga, A. A., Winship, C., Tyler, T. R., Fagan, J., \& Meares, T. L. (2014). The Salience of Social Contextual Factors in Appraisals of Police Interactions with Citizens: A Randomized Factorial Experiment. Journal of Quantitative Criminology, 30(4), 599627. doi: 10.1007/s10940-014-9216-7

Celestin, B. D., \& Kruschke, J. K. (2019). Lay evaluations of police and civilian use of force: Action severity scales. Retrieved from https://osf.io/h6jg3/

Chapman, C. (2012). Use of force in minority communities is related to police education, age, experience, and ethnicity. Police Practice and Research, 13(5), 421-436. doi: 10.1080/15614263.2011.596711

de Leeuw, J. R. (2015). jsPsych: A JavaScript library for creating behavioral experiments in a Web browser. Behavior Research Methods, 47, 1-12. doi: 10.3758/s13428-014 $-0458-\mathrm{y}$

Denwood, M. J. (2016). runjags: An R package providing interface utilities, model templates, parallel computing methods and additional distributions for MCMC models in JAGS. Journal of Statistical Software, 71(9), 1-25. doi: 10.18637/jss.v071.i09

Fiske, A. P., \& Rai, T. S. (2014). Virtuous Violence: Hurting and Killing to Create, Sustain, End, and Honor Social Relationships (Vol. 27). Cambridge University Press.

Friedersdorf, C. (2017a, dec). Footage of a police shooting that jurors chose not to punish. The Atlantic. Retrieved from https://www.theatlantic.com/ politics/archive/2017/12/footage-of-a-police-killing -that-jurors-didnt-punish/547868/\{\\#\}article-comments

Friedersdorf, C. (2017b, dec). A police killing without a hint of racism. The Atlantic. Retrieved from https://www.theatlantic.com/politics/archive/ 2017/12/a-police-killing-without-a-hint-of-racism/ $546983 /$

Gerber, M. M., \& Jackson, J. (2017). Justifying Violence: Legitimacy, Ideology and Public Support for Police Use of Force. Psychology, Crime and Law, 23(1), 79-95. 
Gorner, J., \& Dardick, H. (2016, oct). Citing beating of officer, Chicago's top cop says police are 'second-guessing themselves'. Chicago. Retrieved from http://www.chicagotribune.com/news/local/breaking/ct -citing-beating-of-officer-chicago-s-top-cop-says-police -are-second-guessing-themselves-20161006-story.html

Gray, K., Schein, C., \& Ward, A. F. (2014). The Myth of Harmless Wrongs in Moral Cognition: Automatic Dyadic Completion From Sin to Suffering. Journal of experimental psychology. General, 143(4), 1600-1615.

Gray, K., \& Wegner, D. M. (2009). Moral Typecasting: Divergent Perceptions of Moral Agents and Moral Patients. Journal of Personality and Social Psychology, 96(3), 505-520. doi: 10.1037/a0013748

Gureckis, T. M., Martin, J., McDonnell, J., Alexander, R. S., Markant, D. B., Coenen, A., ... Chan, P. (2015). psiTurk: An open-source framework for conducting replicable behavioral experiments online. Behavioral Research Methods, 1-15. doi: 10.3758/ s13428-015-0642-8

Haas, N. E., de Keijser, J. W., \& Bruinsma, G. J. (2014). Public support for vigilantism, confidence in police and police responsiveness. Policing and Society, 24(2), 224241. doi: $10.1080 / 10439463.2013 .784298$

Haas, N. E., de Keijser, J. W., \& Bruinsma, G. J. N. (2012). Public support for vigilantism: An experimental study. Journal of Experimental Criminology, 8(4), 387-413. doi: 10.1007/s11292-012-9144-1

Hamm, J. A., Trinkner, R., \& Carr, J. D. (2017). Fair Process, Trust, and Cooperation: Moving Toward an Integrated Framework of Police Legitimacy. Criminal Justice and Behavior, $X X(\mathrm{X}), 009385481771005$. doi: 10.1177/0093854817710058

Hickman, M. J., Atherley, L. T., Lowery, P. G., \& Alpert, G. P. (2015). Reliability of the Force Factor Method in Police Use-of-Force Research. Police Quarterly, 1098611115586175-. doi: 10.1177/1098611115586175

Hogan, S. (2017, may). Tulsa officer acquitted in fatal shooting of unarmed black man. Retrieved from https://www.washingtonpost.com/ news/morning-mix/wp/2017/05/18/tulsa-officer-acquitted -in-fatal-shooting-of-unarmed-black-man/?utm\{ $\left.\backslash \_\right\}$term= .c0dcff 495 ece

Iyer, R., Koleva, S., Graham, J., Ditto, P., \& Haidt, J. (2012). Understanding libertarian morality: The psychological dispositions of self-identified libertarians. PLoS ONE, $7(8)$.

Jackson, J., Huq, A. Z., Bradford, B., \& Tyler, T. R. (2013). Monopolizing force? Police 
legitimacy and public attitudes toward the acceptability of violence. Psychology, Public Policy, and Law, 19(4), 479-497. doi: 10.1037/a0033852

Jefferis, E., Butcher, F., \& Hanley, D. (2011). Measuring perceptions of police use of force. Police Practice and Research, 12(1), 81-96. doi: 10.1080/15614263.2010.497656

Johnson, D., \& Kuhns, J. B. (2009). Striking Out: Race and Support for Police Use of Force. Justice Quarterly, 26(3), 592-623. doi: 10.1080/07418820802427825

Kruschke, J. K. (2015). Doing Bayesian Data Analysis: A Tutorial with R, JAGS, and STAN (2nd ed.). Academic Press.

Kruschke, J. K., \& Liddell, T. M. (2018a). Bayesian analysis for newcomers. Psychonomic Bulletin \& Review, 25(1), 155-177. doi: 10.3758/s13423-017-1272-1

Kruschke, J. K., \& Liddell, T. M. (2018b). The Bayesian New Statistics: Hypothesis testing, estimation, meta-analysis, and power analysis from a Bayesian perspective. Psychonomic Bulletin \& Review, 25(1), 178-206. doi: 10.3758/s13423-016-1221-4

Mazerolle, L., Antrobus, E., Bennett, S., \& Tyler, T. R. (2013). Shaping Citizen Perceptions of Police Legitimacy: A Randomized Field Trial of Procedural Justice. Criminology, 51(1), 33-63. doi: 10.1111/j.1745-9125.2012.00289.x

Plummer, M. (2003). JAGS: A program for analysis of Bayesian graphical models using Gibbs sampling.

Salinger, T. (2016, sep). Video released in fatal police shooting of unarmed Oklahoma man Terence Crutcher. Retrieved from https://www. nydailynews.com/ news/crime/video-released-fatal-police-shooting-unarmed -oklahoma-man-article-1.2798435

Schein, C., \& Gray, K. (2017). The Theory of Dyadic Morality : Reinventing Moral Judgment by Redefining Harm. Personality and Social Psychology Review, 1-39. doi: $10.1177 / 1088868317698288$

Schwitzgebel, E., \& Cushman, F. (2012). Expertise in Moral Reasoning? Order Effects on Moral Judgment in Professional Philosophers and Non-Philosophers. Mind and Language, 27(2), 135-153.

Stan Development Team. (2016). RStan: the R interface to Stan. Retrieved from http: / / mc-stan.org

Stewart, E. (2018). Florida shooting: multiple armed officers waited outside during massacre. Retrieved 2018-06-23, from https://www.vox.com/ policy-and-politics/2018/2/24/17048720/florida-shooting -law-enforcement-gun

Sunshine, J., \& Tyler, T. R. (2003). The Role of Procedural Justice and Legitimacy in Shaping Public Support for Policing. Law \& Society Review, 37(3), 513-548. 
Team, R. (2016). RStudio: Integrated Development Environment for R. Retrieved from http://www.rstudio.com/

Tennessee v. Garner, 471 U.S. 1. (1985).

Terrill, W., Alpert, G. P., Dunham, R. G., \& Smith, M. R. (2003). A management tool for evaluating police use of force: an application of the force factor. Police Quarterly, 6(2), 150-171. doi: 10.1177/1098611102250491

Terrill, W., Paoline, III, E. A., \& Ingram, J. (2011). Final Technical Report Draft: Assessing Police Use of Force Policy and Outcomes (Tech. Rep.). National Institute of Justice. Retrieved from https://www.nij.gov/publications/pages/ publication-detail.aspx?ncjnumber $=237794$ doi: NCJNumber: 237794

Thompson, B. L., \& Daniel Lee, J. (2004). Who Cares If Police Become Violent? Explaining Approval of Police Use of Force Using a National Sample. Sociological Inquiry, 74(3), 381-410. doi: 10.1111/j.1475-682X.2004.00097.x

Tyler, T. R. (2006). Why People Obey the Law. New Jersey: Princeton University Press.

Weitzer, R. (2005). Determinants of Public Satisfaction with the Police. Police Quarterly, 8(3), 279-297.

Wikipedia Contributors. (2018). Stoneman Douglas High School shooting. Retrieved from https://en.wikipedia.org/wiki/Stoneman\{ _\}Douglas $\left\{\backslash_{-}\right\}$High $\left\{\backslash_{-}\right\}$School $\left\{\backslash_{-}\right\}$shooting 